\title{
Flame retardant polymer materials: An update and the future for 3D printing developments
}

\author{
Henri Vahabi $^{\mathrm{a}, *}$, Fouad Laoutid ${ }^{\mathrm{b}}$, Mehrshad Mehrpouya ${ }^{\mathrm{c}}$, Mohammad Reza Saeb ${ }^{\mathrm{a}}$, \\ Philippe Dubois ${ }^{\mathrm{d}}$ \\ ${ }^{\mathrm{a}}$ Université de Lorraine, CentraleSupélec, LMOPS, F-57000, Metz, France \\ ${ }^{\mathrm{b}}$ Laboratory of Polymeric \& Composite Materials, Materia Nova Research Center, Place du Parc 23, B-7000, Mons, Belgium \\ ${ }^{\mathrm{c}}$ Faculty of Engineering Technology, University of Twente, P.O. Box 217, 7500 AE, Enschede, the Netherlands \\ ${ }^{\mathrm{d}}$ Laboratory of Polymeric and Composite Materials (LPCM), Center of Innovation and Research in Materials \& Polymers (CIRMAP), Health and Materials Research \\ Institutes, University of Mons, Place du Parc, 23, B-7000, Mons, Belgium
}

\section{A R T I C L E I N F O}

\section{Keywords:}

Flame retardancy

Flame retardants

3D printing

Polymers

Additive manufacturing

\begin{abstract}
A B S T R A T
Fire safety has become a major concern due to the ubiquitous use of polymers. The development of flame retardant polymer materials has consequently experienced a huge growth in market size. New strategies and legislation have also been proposed to save lives and property. The science and economics of flame retardancy, fire regulations, and new technologies are under permanent evolution. This review paper focuses on revisiting and classifying recent developments in the knowledge and technology of flame retardant polymer materials and demonstrating the qualitative and quantitative analyses carried out on their flame retardant properties. In particular, it comprehensively addresses the progress made and the future prospects for designing precise structures via innovative technologies, particularly 3D printing - as the state-of-the-art manufacturing methodology providing innovative features in this realm of research - and their flame retardancy performances. Indeed, the strategies driving the technologies of innovative flame retardant polymer materials and 3D printing technology are approaching a practical juncture in the near future.
\end{abstract}

\section{Introduction}

The immense use of polymer materials including neat polymers together with blends and composites has significantly improved the quality of our lives. However, fire hazards arising from the highly flammable nature of polymers has been a major concern in all sectors, $e$. g. building and constructions, transportation, and aerospace applications [1,2]. For instance, the Grenfell Tower tragedy in London demonstrated that fire hazards need to be managed [3]. Flame retardancy has therefore become a critical performance parameter to be considered in the design of polymers [4]. Analysis of the evolution of flame-retardant polymers involves exploring the role of conventional as well as new flame-retardant systems used in polymer technology. Flame-retardant nanomaterials have been provisionally acknowledged by some developers/researchers as solutions to the insufficient flame retardancy of polymer systems, although understanding the individual and/or simultaneous effects of flame retardants (FRs) and the mechanisms controlling their functions are still being debated $[5,6]$. Further difficulties have also been encountered in understanding the flame retardancy performance of additives in polymer matrices as a consequence of the lack of a universal criterion for the analysis of experimental data, combined with some judgments arbitrarily made on small datasets [6]. Moreover, the circumstances of modern material design and people's high expectations, combined with the legislation imposed by governments to protect human beings, buildings, and the environment against fire, emphasize the need to review these new materials and their processing/manufacturing routes from the flame retardancy angle [7].

Flame-retardant polymer materials have been comprehensively studied in a previous work [8]. The development of increasingly complex and sophisticated flame-retardant systems is the result of the adaptation of the plastics industry to various societal changes and evolutions. First, the collective awareness of the need to conserve the environment, together with public and occupational health and safety, led to the prohibition of some materials. This is the case of some halogenated flame-retardant additives that have been banned from the

\footnotetext{
* Corresponding author.

E-mail address: henri.vahabi@univ-lorraine.fr (H. Vahabi).
} 
market because of toxicological and environmental issues $[9,10]$. The halogenated FRs were highly effective at relatively low incorporation content; therefore, their replacement has proved to be complicated and often relatively ineffective, especially in some applications like fabrics and films $[11,12]$. Moreover, the products need to be added at relatively low content to preserve film transparency and enable weaving. In parallel, fire safety rules are undergoing major changes, with which it is very difficult for the development of new FRs to keep pace [13]. Consequently, the industry is looking for efficient, cost-effective, and environmentally-friendly flame-retardant systems [14].

The development of highly efficient FRs is a state-of-the-art issue that needs to critically meet the requirements of new technologies. For example, in the case of electric cars, the development of new generations of batteries, which will provide higher energy density, faster charging and therefore a significant increase in range, requires the development of new materials capable of securing the transmission of data and energy at high voltages [15]. These challenging new materials must therefore present good mechanical, electrical, and fire properties. Additive manufacturing (AM) is another example showing how the emergence of new technologies can present an opportunity for developing new materials $[16,17]$. Industrial manufacturers have been convinced by $3 \mathrm{D}$ printing technology and use it more and more to produce complex products for technical applications [18]. These 3D-printed products must meet the same flame retardancy requirements as injected/molded ones. However, not all the conventional flame-retardant materials used for injection/molding can be used in 3D printing technology.

Modern manufacturing methods enable the production of advanced materials via innovative processes, which are known for being versatile, less energy-consuming, and more environmentally friendly [19]. Accordingly, 3D printing can be applied as an innovative and highly flexible tool for producing complex shapes using various materials as well as metals, polymers, ceramics, or concretes [20]. Adding a time to the 3D printing process, so-called four-dimensional (4D) printing, can provide a unique opportunity to design and develop tunable time-dependent products that can either be deformed in shape over time or reverted to an initial design, exposed to the environmental stimuli such as temperature or light [21,22]. The ability to combine design and technology in AM has enabled the development of programmable self-assembly materials for advanced systems. Among printable materials, polymers have received particular attention due to their variable microstructure, providing a vast range of properties as well as adaptability to various 3D printing machines [23]. Polymer materials for 3D printing come in the form of powder, resin, filaments, or reactive monomers [24]. From a global point of view, the resulting polymer materials are categorized as thermoplastics, thermosets, and elastomers.
Nevertheless, depending on the processing method, there are some additional requirements to be satisfied for choosing the correct additives and processing conditions, such as the toxicity of materials, processing limitations, and safety requirements.

Scientific reports on 3D printing as well as flame-retardant polymer systems have received continued attention in the literature over the past two decades, Fig. 1. Despite the sharp upward trend shown in Fig. 1, there is still a long way to go before achieving a desirable level of flame retardancy in polymers shaped via 3D printing or amalgamations between flame retardancy and 3D printing technologies. The complications associated with the design and manufacture of advanced flameretardant materials, along with the printability of flame-retardant polymer materials, particularly need be taken into consideration. To date, the control of the flammability and printability of polymers has not been systematically addressed or harmoniously discussed. Hopes and concerns in this regard are only vaguely identified in view of the uncertainties of selecting flame-retardant additives and polymers, manufacturing machines and processing conditions, the shape and geometry of materials, and printing strategies. The future of flameretardant polymer materials would benefit from a reconsideration of both the materials themselves and the manufacturing parameters. For instance, the 3D printing of flame-retardant polymer materials could adversely impact the lightness of the structures developed and the ability to design anomalous or intricate geometrical shapes. The large quantity of additives required to achieve better FRs has been recognized as a serious concern, both practically and economically. Material, manufacturing, and economic parameters may therefore need to be harmonized to enable the design of high-performance flame-retardant polymer materials.

\section{Flame-retardant polymer materials}

The evolution of flame-retardant polymer materials can be viewed from various perspectives, including materials (Fig. 2), and processing techniques and applications (Fig. 3). Polymer selection for flameretardant devices/systems depends on the application and the conditions to which materials are exposed. For example, ethylene vinyl acetate (EVA) thermoplastic copolymers have been widely used in the cable industry [25], while epoxy resins are versatile thermoset polymers much used as protective coatings and adhesives [26,27]. Since the processing of these polymers and their compatibility with additives follow different strategies, material selection is as a crucial variable in designing flame-retardant EVA- and epoxy-based materials. Moreover, additive selection for a given polymer depends on the cost, polymer-filler interaction, and flame retardancy level expectations. The classification of (a)

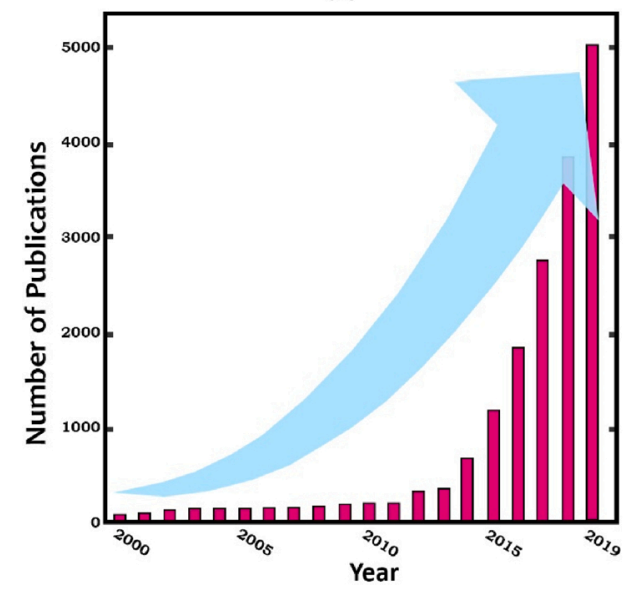

(b)

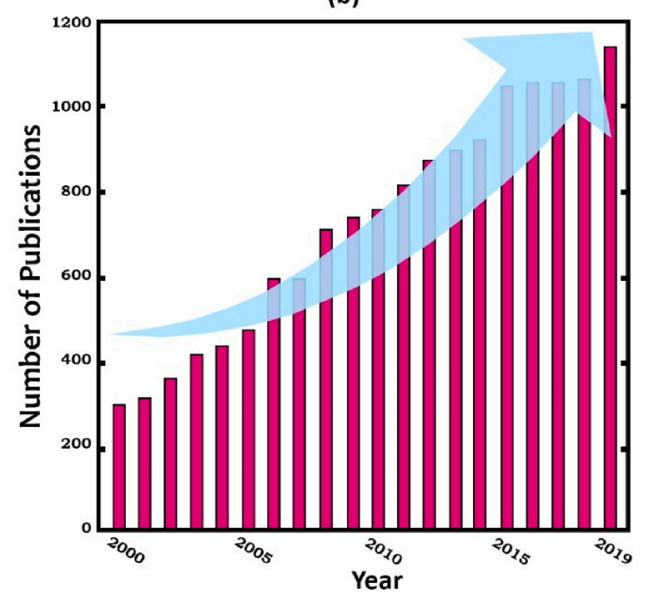

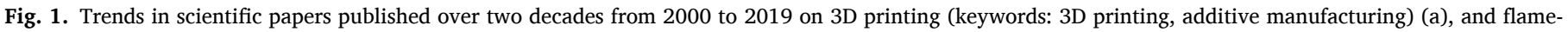
retardant polymer materials (keywords: flame retardant, fire retardancy, polymer) (b), according to SciFinder (14th March 2020). 


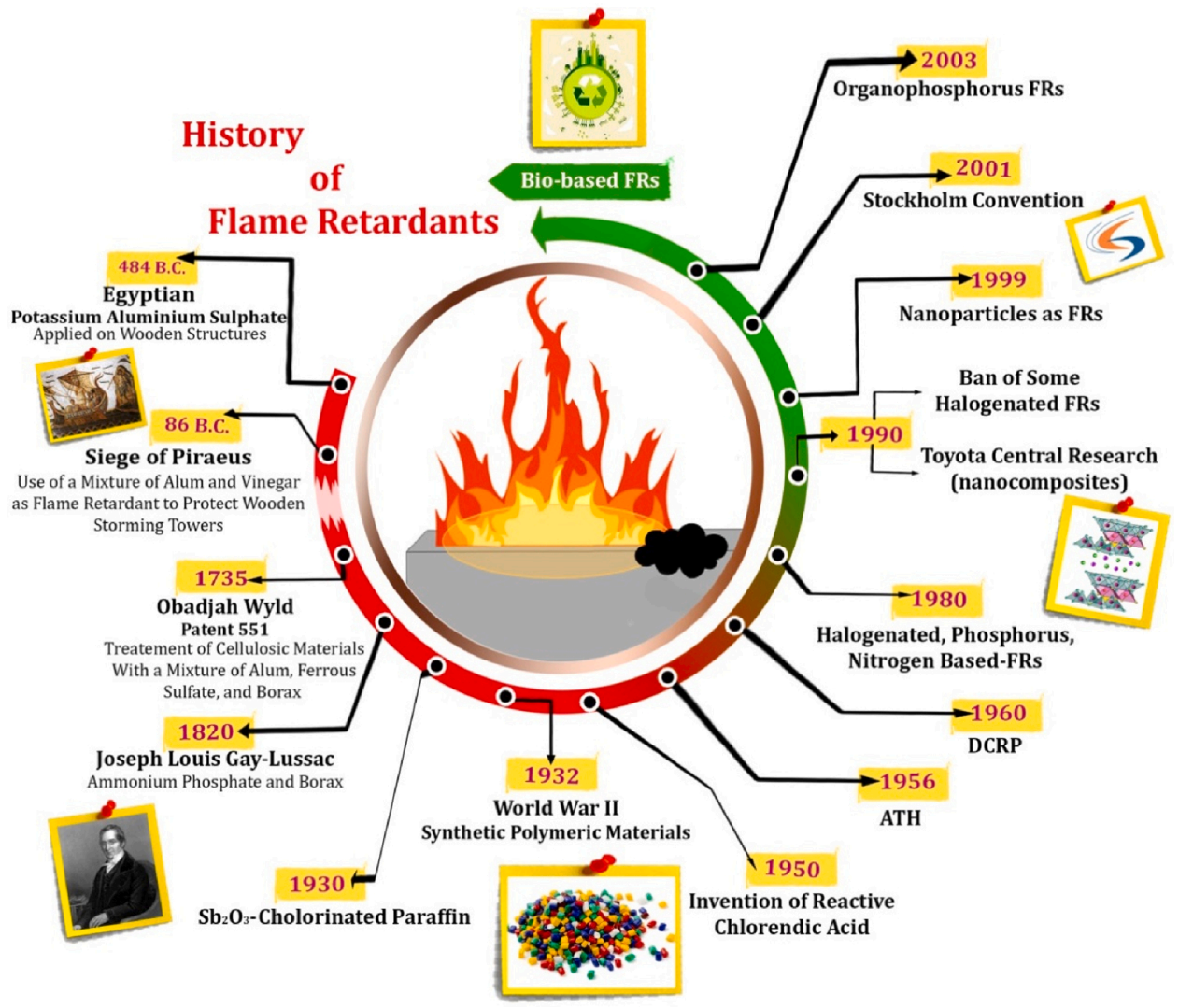

Fig. 2. Historical evolution of FRs: the history of attempts to protect materials from goes back to thousands of years ago, $c a .484$ B.C., when the Egyptians used minerals to make wood and cotton more fire-resistant. Afterward, during the siege of Piraeus (86 years B.C.), alum solutions were applied to wooden battleships. Hundreds of years later, the first flameretardant material patent was registered by $\mathrm{O}$. Wyld in 1735 [28]. J.L -Lussac greatly contributed to the science of fire by working on the flame retardancy of curtains in Parisian theaters [29]. Much later, flame retardancy science took on a new dimension with the invention and development of new polymers, and has continued to mature; some non-exhaustive key-events from 1930 to now are presented in this figure, demonstrating the continual evolution of flame retardancy science and technology. This evolution has been considerably affected by some major events such as the ban on some halogenated FRs and the Stockholm Convention.

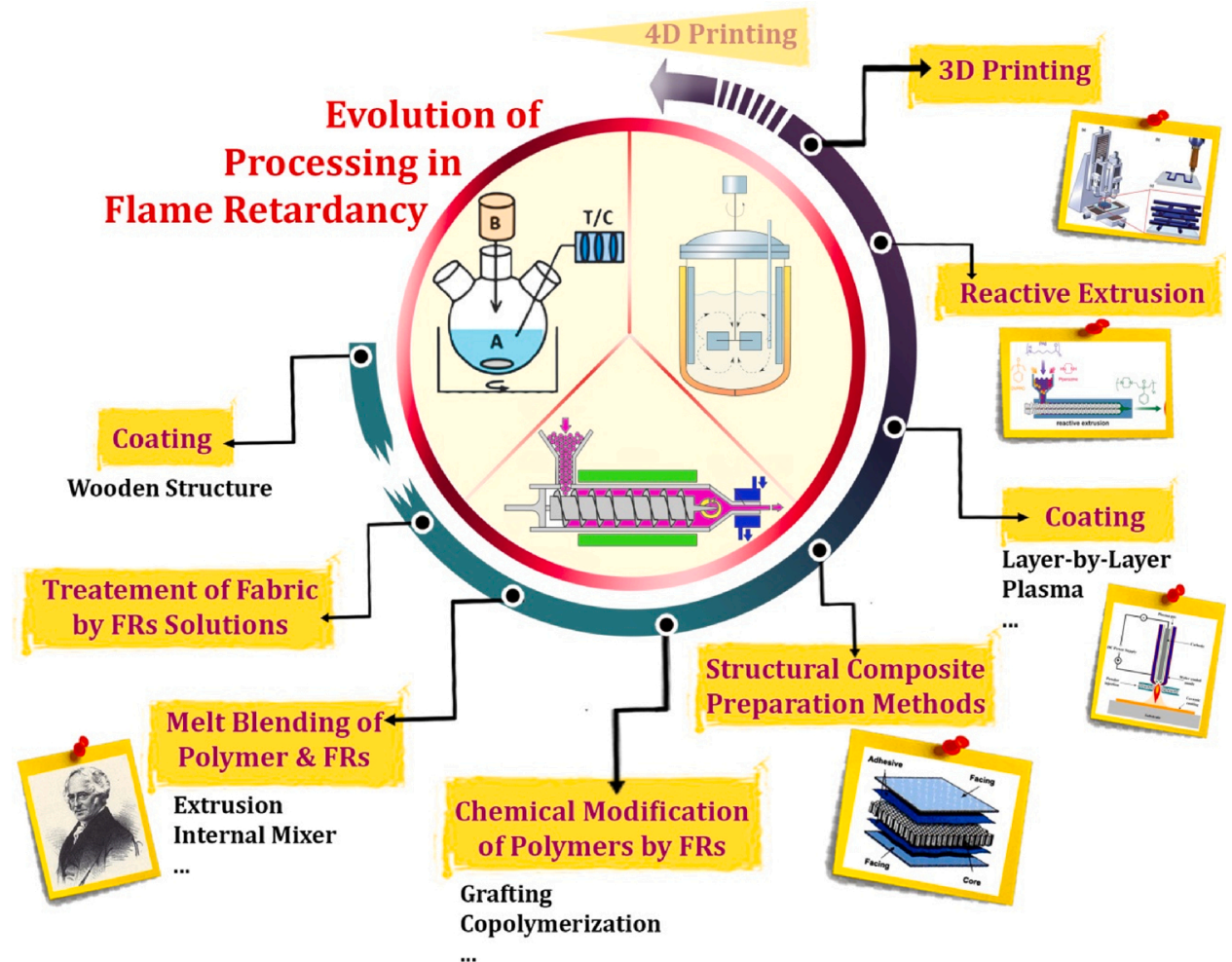

Fig. 3. Evolution of processing methods examined in the era of flame retardancy: In parallel to the development of new FRs, the processing technology has evolved considerably and is still being developed. From the simple coating treatment in Ancient Egypt to the new 3D and 4D printing technologies, FRs and processing methods have mutually adapted to each other. 
polymer materials in terms of flame retardancy performance enables the selection of the best material among the bewildering arrays of different possibilities. In this regard, the use of reliable indices for modelling the fire performance of a polymer is of prime importance.

\subsection{Flame retardancy of polymers}

The required level of resistance of a polymer against fire depends not only on the type of additive but also on the genealogy of the polymer and the final application. Moreover, passive and active fire protection requirements such as structural design and smoke detection sensors, as well as the choice of material, play key roles [30,31]. Typically, regional and international safety and fire protection laws that affect the selection of flame-retardant additives for various polymers are included in decision-making policies. To take the first step in the flame retardancy classification of polymers, a comprehensive view of the various types and grades of polymers is required. Due to the extremely broad variety of polymers and the dependency of their behaviors on their chemistry and molecular weight distribution, polymers can be classified in different ways. They can be treated in function of their source (natural, synthetic, and semi-synthetic polymers), structure (linear, branched-chain, and crosslinked polymers), mode of polymerization (addition and condensation polymers), and the molecular forces holding the monomers in the chain (elastomers, thermoplastics, thermosetting polymers). From the flame retardancy point of view, a classification based on thermoplastic and thermoset polymer materials enables a judicious selection of additives.

Thermoplastics can further be classified as amorphous (like poly (methyl methacrylate) (PMMA), and polycarbonate (PC)) or crystalline (like polypropylene (PP) and poly(ethylene terephthalate) (PET)) plastics. Melt extrusion of thermoplastics with flame-retardant additives is the most convenient way to develop flame-retardant polymer materials. Typically, it is difficult to provide crystalline polymers with flame retardant properties. By contrast, the enchainment of flame-retardant molecules in the propagation of oligomer chains during the course of polycondensation or grafting the flame-retardant substances onto growing chains are more frequent in thermosetting polymers [32,33]. In thermoset materials, the dependency of properties on the crosslinking reactions taking place between the organic resin and curing agent, also need to be taken into account in design criteria [34,35]. However, apart from a limited number of high-performance polymers such as polyetheretherketone (PEEK) with a high glass transition temperature $\left(\mathrm{T}_{\mathrm{g}}\right)$ above $140^{\circ} \mathrm{C}$, polyetherimide (PEI), poly(phenylene sulfone) (PPSU), polybenzoxazole (PBO), polybenzimidazole (PBI), polyimide (PI), polyamide-imide (PAI), poly(p-phenyleneterephtal-amide) (PPTA), and polypyridobisimidazole (PIPD), almost all general-purpose polymers are highly flammable $[36,37]$. Therefore, the additive selection is of prime importance in developing flame-retardant polymer materials.

\subsection{Additive selection for flame-retardant systems}

Additive selection for achieving flame-retardant polymer materials necessitates identifying the physical and chemical functions of additives in polymers. The principal families of flame retardants will be reviewed below.

\subsubsection{Mineral FRs}

According to a 2017 market study by IHS Consulting, Fig. 4, minerals represent the largest segment in the market of FRs. This category includes metallic hydroxides, boron-based additives, hydroxycarbonates and even inert fillers. The incorporation of any type of inorganic filler can generally reduce the content of combustible polymer or increase both melt viscosity and thermal conductivity. However, inert fillers are sometimes used in combination with other FRs, namely metallic hydroxides, specifically aluminum tri-hydroxide (ATH) and magnesium dihydroxide $(\mathrm{MDH})$. When heated, metal hydroxides release water

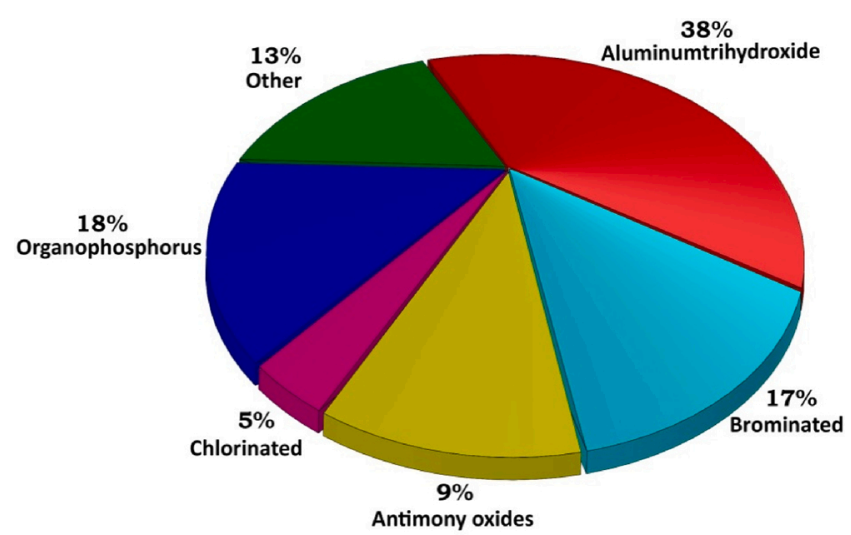

Fig. 4. Global flame retardants (FRs) market categorized based on the chemistry [38].

through thermal decomposition. The absorption of heat during endothermic process decelerates the thermal decomposition of polymers. Moreover, the condensed water vapor released during the combustion contributes to the dilution of the combustible gases formed during combustion. The endothermic decomposition temperature of the hydroxide must take place below the polymer processing and decomposition temperature ranges. Aluminum hydroxide is active at around $180-200^{\circ} \mathrm{C}$, while $\mathrm{MDH}$ decomposes at higher temperatures ( $\left.300^{\circ} \mathrm{C}\right)$. Calcium hydroxide $(\mathrm{CDH})$ is an interesting solution, as a relatively inexpensive hydroxide that endothermically decomposes at higher temperature $\left(\sim 400^{\circ} \mathrm{C}\right)$. Combining $\mathrm{CDH}$ with ATH or $\mathrm{MDH}$ prolongs water release beyond $300^{\circ} \mathrm{C}$.

Hydroxycarbonates have the advantage of combining both hydroxide and carbonate in their chemical structure. This provides them with the ability to release both water and $\mathrm{CO}_{2}$ by endothermic decomposition. However, their use is limited because the thermal decomposition of the carbonate part occurs at higher temperatures; only magnesium carbonate, which decomposes at $550{ }^{\circ} \mathrm{C}$, could present some interest in flame retardancy. Moreover, in order to achieve significant improvement in flame-retardant properties, a large amount (more than $50 \mathrm{wt} . \%$ ) of metallic hydroxides and hydroxycarbonates must be blended in the polymer, which may affect the other functional properties of the final material.

Boron-based FRs present another family of inorganic flame-retardant additives. Zinc borates are frequently used due to their endothermic decomposition properties, occurring between $290^{\circ} \mathrm{C}$ and $450{ }^{\circ} \mathrm{C}$ and releasing water, boric acid $\left(\mathrm{H}_{3} \mathrm{BO}_{3}\right)$, and boron oxide $\left(\mathrm{B}_{2} \mathrm{O}_{3}\right)$.

\subsubsection{Halogen-based FRs}

Halogen-based FRs represent the second largest family of FRs [39]. They decompose into highly reactive free radicals, acting in the gas phase by scavenging the polymer degradation radicals responsible for maintaining the combustion process. Halogen-based FRs can either be blended with polymers (additive pathway) or structurally added as units of the polymer backbone during the course of the polymerization reaction (reactive pathway).

Some halogenated FRs have been banned because they have been shown to present environmental and health issues [40]. Polychlorobiphenyls (PCBs) were the first halogenated FRs to be banned, in the 1970s, because of their toxicity and persistence in the environment. Their replacements, polybrominated biphenyls (PBBs), with a similar chemical structure, were also banned for the same reasons [41-43]. The withdrawal of these two products paved the way for the development of new halogenated FRs, which are classified in three categories: (i) small molecules, (ii) oligomeric or polymeric forms, and (iii) reactive FRs.

In the category of small halogenated FRs, polybromodiphenyl ether (PBDE), and penta-, deca- and octa-PBDE were among the most widely 
Table 1

Chemical structure of some of the commonly used halogenated FRs.

Polychlorinated biphenyl (PCB)

used, Table 1 . These products were classified as persistent organic pollutants and penta- and octa-BDE were the first to be banned, in 2004, later followed by deca-BDP. Hexabromocyclododecane (HBCDD) is another widely used brominated FRs that was found to be very toxic and classified as a persistent organic pollutant by the Stockholm Convention. Its production and use were banned from 2014 with specific exemptions for expanded and extruded polystyrene in buildings. Tetrabromobisphenol A (TBBP A) has also been risk-assessed under the European Union's existing substances program and recommendations have been made to restrict its use with a limit value of $0.1 \mathrm{wt} . \%$, because of its potential endocrine-disrupting properties and persistence in the environment [44].

Using small molecules exposes the risk of easier migration of these additives from the polymer during use or at the end of its life [45]. These products may therefore come into contact with users or be released into the environment. Polymeric-halogenated compounds could be considered as a better alternative [46]. They are too large to easily migrate from the polymer and penetrate cell membranes but may cause problems during burning or incineration. Unlike small halogenated molecules, which can be used in different polymers, the chemical structure of oligomeric and polymeric forms must be adapted to the host polymer to achieve good compatibility. Some polymeric-brominated FRs are used for polystyrene, polyesters, polycarbonates, polyamides, and epoxy thermosets $[47,48]$.

\subsubsection{Phosphorus-based FRs}

Phosphorus-based compounds represent the third most used family of the FRs, but the fastest growing market segment $[49,50]$. They have greatly benefited from their lack of toxicity compared to halogenated FRs, for which they considered to be the best substitutes.

Like halogenated FRs, they can be used in both additive and reactive pathways. Phosphorus-based FRs can be divided into two classes: organic and inorganic compounds, covering various compounds in which phosphorus is present in different oxidation states from 0 to 5 . Phosphorus acts in either the condensed or the gas phase. Because of this dual role, the flame-retardant action of phosphorus cannot be described by a single mechanism. Phosphorus-based FRs have been the subject of several reviews [51-53]. In this section, a brief, updated survey will be presented.

Red phosphorus together with ammonium polyphosphate (APP) are the most well-known inorganic phosphorus-based FRs. The former, even in small quantities below $10 \mathrm{wt} . \%$, shows promising flame-retardant performances, particularly in oxygen- and/or nitrogen-containing polymers. In the presence of nitrogen and oxygen and at high temperatures, red phosphorus is transformed into phosphoric acid, phosphoric anhydride and later polyphosphoric acid, which promotes char formation by a dehydration reaction with the polymer [54]. Italmatch Chemicals, one of the main producers of red phosphorus, has developed new, colorless inorganic phosphorus FRs (Phoslite ${ }^{\circledR}$ series), based on aluminum or calcium hypophosphite salts. The various grades developed can be used in different polymers, from polyolefins and polyvinyl chloride (PVC) to polyamide (PA), PC and polyurethane (PU) foams.

APP is an inorganic salt resulting from the reaction of polyphosphoric acid with ammonia, available in two crystalline forms. The first (APP I) contains short, linear chains and is also more water-sensitive and less stable when heated $\left(150^{\circ} \mathrm{C}\right)$ than the second, longer-chained form APP II $\left(300^{\circ} \mathrm{C}\right)$. Both APP forms decompose into polyphosphoric acid (which promotes char formation) and release ammonia (which contributes to gas phase dilution) but at different temperatures.

The range of organic phosphorus-based FRs is very broad and contains products in which phosphorus is present in different oxidation states, i.e. phosphate, phosphonate, phosphinates and phosphine oxides. The condensed phase action, involving the formation of an insulating char layer, is the most common mode of action of these products. The formation of this char results from the oxidation of the phosphorus compounds and also from the interaction with the polymer. Achieving appropriate flame-retardant behavior depends on the timing between the decomposition of polymer chains and the action of the flame retardant used. The chemistry of phosphorus and the thermal and fire behavior of the polymer together determine the fire-retardancy performance. Therefore, phosphorus-based FRs are more specific to polymer chemistry than halogenated FRs. However, in some cases, albeit few in number, some organophosphorus FRs exhibit gas phase action. These cases are very limited because the vaporization of phosphorus must take place at relatively low temperature but not during melt processing to prevent phosphorus loss and phosphine formation.

Aluminum diethyl phosphinate (DEPAL) and 9,10-dihydro-oxa-10phosphaphenanthrene-10-oxide (DOPO) are the best-known organophosphorus compounds acting in the gas phase. DEPAL mostly acts in the gas phase by a flame inhibiting mechanism [55], owing to its volatilization without decomposition [56]. Some researchers have reported on the action of DOPO in the gas phase in combination with condensed-phase action, fueled by the reactive species (PO) formed during thermal decomposition [51]. However, phosphorus-containing FRs are not a miracle solution because their effectiveness is variable depending on the polymer matrix.

\subsubsection{Nitrogen-based FRs}

Nitrogen-based flame-retardant additives form an interesting and varied family of FRs. Melamine and its derivatives are the best known, but other nitrogen-containing FRs, such as $\mathrm{N}$-alkoxyamines and azoalkanes show also interesting flame-retardant effects. Melamine is an inexpensive nitrogen-rich thermally-stable organic product $\left(\mathrm{C}_{3} \mathrm{H}_{6} \mathrm{~N}_{6}\right)$, containing $67 \mathrm{wt} . \%$ nitrogen and presenting a melting point of $345^{\circ} \mathrm{C}$ and sublimating at around $350^{\circ} \mathrm{C}[57,58]$. Its flame-retardant effect lies in its capacity to (i) absorb significant amounts of heat during its 
endothermic sublimation, (ii) release inert ammonia which dilutes oxygen and combustible gases in the gas phase and (iii) form a thermally stable residue.

Melamine phosphate covers a wide range of products (melamine orthophosphate, melamine poplyhosphate, dimelamine orthophosphate, dimelamine pyrophosphate and dimelamine pyrophosphate). However, not all such ingredients are usable as FRs in plastics because of their low thermal stability. Melamine phosphate (MPP) is the most interesting for such applications. MPP decomposes thermally by releasing heat during condensed phase action, and also contributes to the dilution of the gas phase together with assisting protective char layer formation owing to the presence of phosphoric acid. Melamine borate (salt of melamine and boric acid) acts as char promotor when an auxiliary FRs additive, e.g. metallic hydroxide or a phosphorus FR like APP is used. Melamine cyanurate is the salt of melamine and cyanuric acid, which acts in a totally different manner. It is mainly used in polyamides and degrades when burnt to promote the formation of noncombustible flow dripping. This allows the polymer to move away from the flame zone and no longer act as a fuel source. Due to such behavior, melamine cyanurate does not effectively work in filled polyamides, such as glass-fiber reinforced PA, that do not flow easily.

In addition to melamine-based FRs, N-alkoxyamines (N-O-C) and azoalkanes $\left(\mathrm{R}_{1}-\mathrm{N}=\mathrm{N}-\mathrm{R}_{2}\right)$ are a novel family of nitrogen-containing FRs acting by means of completely different mechanisms [59]. These FRs form reactive radical species during their decomposition that interact with free radicals formed during the combustion process.

\subsubsection{Organosilicon-based FRs}

Organosilicon compounds are a broad family of organic compounds containing carbon-silicon bonds. Organosilicon compounds can provide flame retardant protection as protective top-layers once burnt. This barrier may be formed through in-situ silica domains produced during the thermal decomposition of silicon and its derivatives. The in-situ production of a ceramic layer prevents the volatilization of combustible products formed during polymer degradation [60]. The combination of organosilicon FRs with phosphorus-based ones, by simple blending or designing new additives containing both silicon ( $\mathrm{Si}$ ) and phosphorus, is an effective strategy for obtaining superior flame-retardant performances thanks to the combined effect of both ceramic and char layers. The Web-based Product Selector for combinations of phosphorus, inorganic and nitrogen FRs (denoted as PINFA) gives a complete list of non-halogenated commercially available FRs in the function of the polymer matrix [61].

\subsubsection{Bio-based FRs}

The search for better performances is not the only driving force behind the development of new FRs. Improving the fire performance of polymers is a major concern because of the need to reconcile the reduction of fire risk with environmental concerns and the necessity to reduce the ecological-footprint of materials. All these additional constraints have encouraged the emergence of a new class of sustainable, natural and renewable flame-retardant solutions [33,62,63].

In the category of renewable molecules that can directly be used as flame-retardant agents, proteins, deoxyribonucleic acid (DNA) and phytic acid are the most studied. Casein, hydrophobins and whey proteins are well-known proteins that promote char formation when used as coatings on cotton fabrics [64-66], but due to different mechanisms. The presence of casein (a phosphorus-containing molecule) and hydrophobins (sulfur and nitrogen-containing molecules) promotes a cellulose char forming pathway owing to the actions of phosphoric or sulfuric acids respectively, while whey proteins enhance cellulose flame-retardant properties due to their oxygen barrier effect and high moisture content.

Phytic acid is a phosphorus-rich liquid (28 wt.\%) present in plant seeds. It can be advantageously used as a coating on cotton fabrics using layer-by-layer assembly in combination with chitosan [67] or nitrogen- and silicon-based compounds [68] to form charred residues. Its positive flame-retardant effect has also been proved in coatings on other fabrics such as wool [69] and poly(lactic acid) (PLA) [70] fabrics. The direct incorporation of phytic acid in polymers is limited because of its ability to migrate from the material due to its liquid form. Using phytate salts has been shown to present an interesting way to overcome this limitation. Among the various metallic phytate salts, aluminum phytate shows a superior flame-retardant effect in PLA owing to its ability to promote fast formation of the homogenous charred layer [71].

Other bio-based products are also of interest as feedstocks for the development of FRs [62], Fig. 5. Some well-known cases are bio-based aromatic compounds such as lignin [72,73] and tannins [74,75]. These compounds have the ability to form char during their pyrolytic decomposition owing to their aromatic structures. However, this char is not resistant under aerobic conditions and fails to provide effective protection. Increasing the protective effect of bio-based FRs principally requires the combination of green aromatic and phosphorus FRs, processed through reactive or additive pathways, prior to char thermo-oxidative stability enhancement.

Flame retardancy can also be achieved using saccharide-based products, such as cellulose, starch, and chitosan. Like aromatic compounds, these materials are able to produce char under some conditions, especially when combined with phosphorus [62]. There are also some reports showing that bio-based flame-retardants are superior to conventional flame retardants. Reti et al. [76] evaluated the flame-retardant behavior of intumescent systems based on APP amalgamated with pentaerythritol (PER) or bio-based additives (starch and lignin are examined). They highlighted that combining APP with lignin or starch decreases LOI, but the value of LOI was still acceptable (above $32 \%$ ) and a superior UL-94 classification was achieved compared with that obtained with APP/PER (V0 compared to V2).

\subsection{Integration of flame retardants into polymers}

Polymer materials resist against fire in three different ways. The first strategy uses flame retardants as additives to impart the resistance of the polymer matrix against fire. The additive pathway, consisting of the physical blending of polymers with FRs, is frequently used in developing flame-retardant polymer materials. The second approach, less widely used, consists in using the flame retardant in its reactive form to attach it covalently to the polymer chain. This may be achieved by direct integration of FRs (mostly reactive halogenated or phosphorus-based molecules) into one system during the polymerization process, as chain extenders or by grafting them on existing polymers. The resulting material can be judged indirectly in terms of the homogeneous dispersion of FR agent at molecular level. The chemical modification of polymers, by incorporation of molecules presenting flame-retardant effect within the macromolecular chain [77] is a very promising way to overcome the migration of FR additives [45], and to enable the development of non-opaque flame-retardant materials [78]. Moreover, using a reactive pathway can prevent the deterioration of the polymer's mechanical properties caused by the presence of heterogeneous FR additives, and improve its processability (for example in the production of fibers or films) and transparency. This approach is widely used in thermoset materials and PU foams. In the case of thermosets, phosphorus-based molecules may be added as monomers or curing agents, whereas in the case of polyurethanes, phosphorus is mainly incorporated via polyol [79]. However, the incorporation of reactive flame-retardant agents is limited in the case of thermoplastic materials, in which phosphorus could be added during the polymerization step, as a chain extender or by grafting on the polymeric chain $[80,81]$. Furthermore, the chemical modification of polymers is a more expensive and complicated process than 'simple' physical mixing, requiring in-depth knowledge of polymerization and chemical grafting processes. The reactive pathway can affect other properties of polymers for example their crystallinity, $\mathrm{T}_{g}$ or thermal stability. 


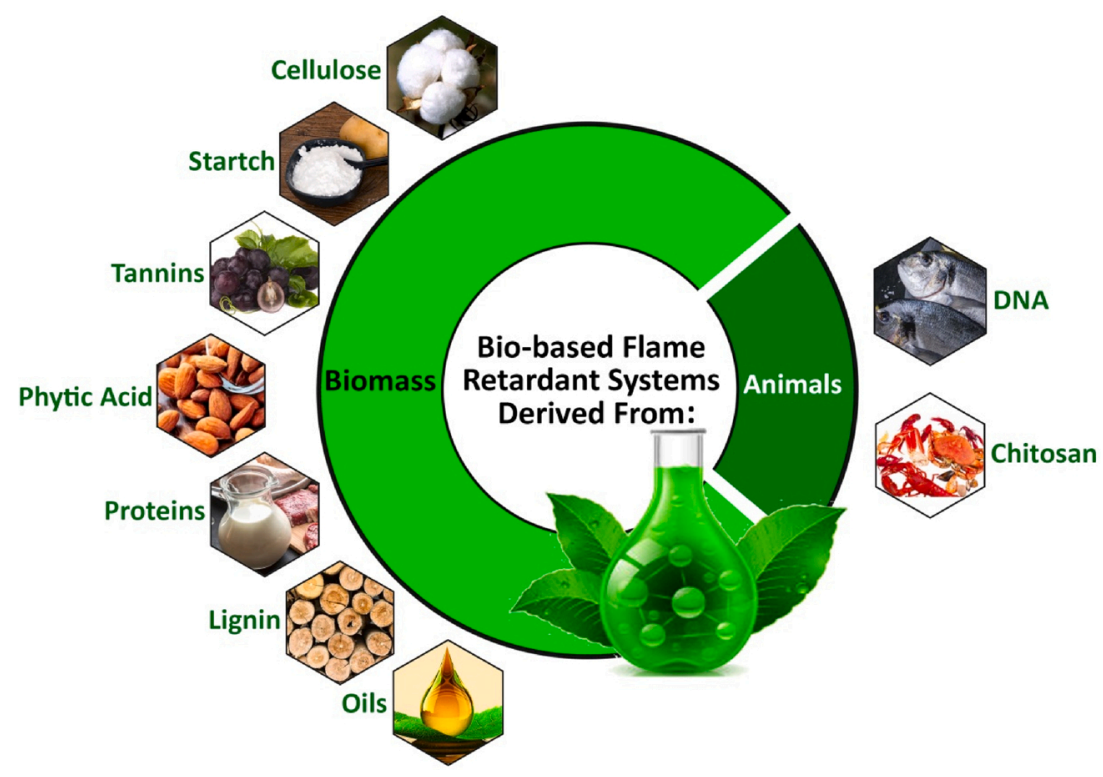

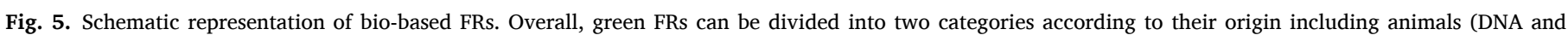

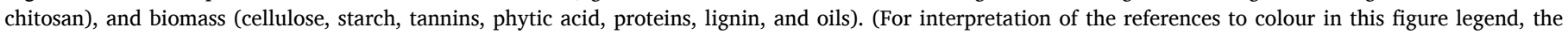
reader is referred to the web version of this article).

Concerning the technology of reactive addition of FRs into polymers, reactive extrusion (REX) is a promising way to develop inherent thermoplastic flame-retardant polymers by reactive pathways [82]. REX is a continuous solvent-free process that enables the handling of difficult-to-process materials (presenting high viscosity) owing to the high degree of mixing applied during the extrusion. The choice of the chemical modification method for REX depends on the nature of the polymer processed. For a commercially available polymer, the molecules providing the fire-retardant protection can be incorporated in two ways, (i) by grafting onto the macromolecular chain or (ii) by enchainment as chain extenders. The second reactive pathway requires polymer chains end-capped by reactive functions. Interestingly enough, such reactive end-groups can be generated in-situ through thermal degradation during melt processing. For example, this is the case with polyamides, polyesters and polycarbonates.

Grafting onto the macromolecular chain can be considered for polymers that contain reactive functional groups pending along the polymer backbone. Such grafting can also be performed on polymer chains without any reactive functions, such as polyolefins. In this precise case, a free-radical grafting process can occur, abstracting hydrogen free-radicals and allowing in a concomitant step the grafting of reactive molecules along the chain. This chemical grafting reaction can be carried out in one step, i.e. direct grafting of the flame-retardant molecule, or in two steps including free-radical grafting a reactive compound such as maleic anhydride followed by grafting a flame-retardant molecule via the ring-opening of the anhydride moiety. It should be noted that the use of REX for developing flame-retardant polymers remains relatively limited even if the chemical modification route shows promising results in developing flame-retardant polymer materials.

PLA can easily be flame retarded by REX. Several works have demonstrated the feasibility of improving its flame-retardant properties by enchainment of phosphorus-based monomers in the backbone of a given polymer chain via reactive processing [80]. All these reactions could be performed by REX. Mincheva et al. [77] described a method for developing in-situ flame retardant PLA. In the first stage, a bifunctional DOPO-based diamine was synthesized, then the product was used as an initiator of ring opening polymerization (ROP) of L,L-lactide (L,L-LA) in the bulk, and lastly a bulk chain-coupling reaction was accomplished between the thus-obtained phosphorylated-PLA oligomers and hexamethylene diisocyanate (HDI) through REX. The results obtained showed that phosphorylated-PLA exhibited superior flame-retardant properties with respect to the commercially available PLA, featured by a lower pHRR, total heat release (THR), and V-0 category as per UL-94 test. Moreover, the comparison of flame-retardant properties obtained with phosphorylated-PLA and PLA composites containing the bi-functional DOPO-based diamine as simple additive confirmed the efficacy of the reactive pathway.

The incorporation of phosphorus into PLA chains can also be achieved by using functional phosphorus-based molecules as chain extenders. Ethyl phosphoro-dichloridate has been successfully used by Wang et al. [83] with dihydroxyl terminated pre-PLA used at $10 \mathrm{wt} . \%$ with virgin PLA. It reduced PHRR and prolonged the time to ignition (TTI) in cone calorimeter tests. The V-0 classification in the UL-94 test, and a limiting oxygen index (LOI) of 35 were also indicative of the successfulness of the idea. REX can also be used for the preparation of phosphorylated-macromolecules in the presence of another polymer. Simonetti et al. [84] prepared phosphorylated-polyamide 6 (PA6) via a Michael-addition reaction of divinylphenylphosphine oxide and piperazine by REX. The materials obtained, physical blends of PA and phosphine oxide macromolecules, presented non-leaching behavior and superior LOI values than virgin PA. It is worth mentioning that the phosphorus was not covalently linked to the PA.

In the third strategy, polymer composites are protected against fire by making use of a protective coating on the surface of the polymer exposed to fire as a flame-retardant material. Such protection of the surface to avoid or at least reduce the flammability of polymers has been occasionally investigated $[85,86]$. Since polymers are inherently flammable and propagate fire during burning, basic knowledge is required about the mechanisms of flame retardant actions in polymer systems.

\subsection{Flame retardant actions and evaluation of flame retardancy}

During the combustion of flame-retardant polymers, FRs decompose, with several possible scenarios of action in the condensed and/or gas phases, Fig. 6. The action of a flame retardant is dependent on its chemical nature as well as its chemical interaction with the polymer matrix. In the condensed phase, three actions are possible: modifying the decomposition pathway of polymers to produce less combustible volatiles and more char and; thus the formation of a barrier or protective layer on the surface of polymer, the cooling effect, and melt dripping. A 


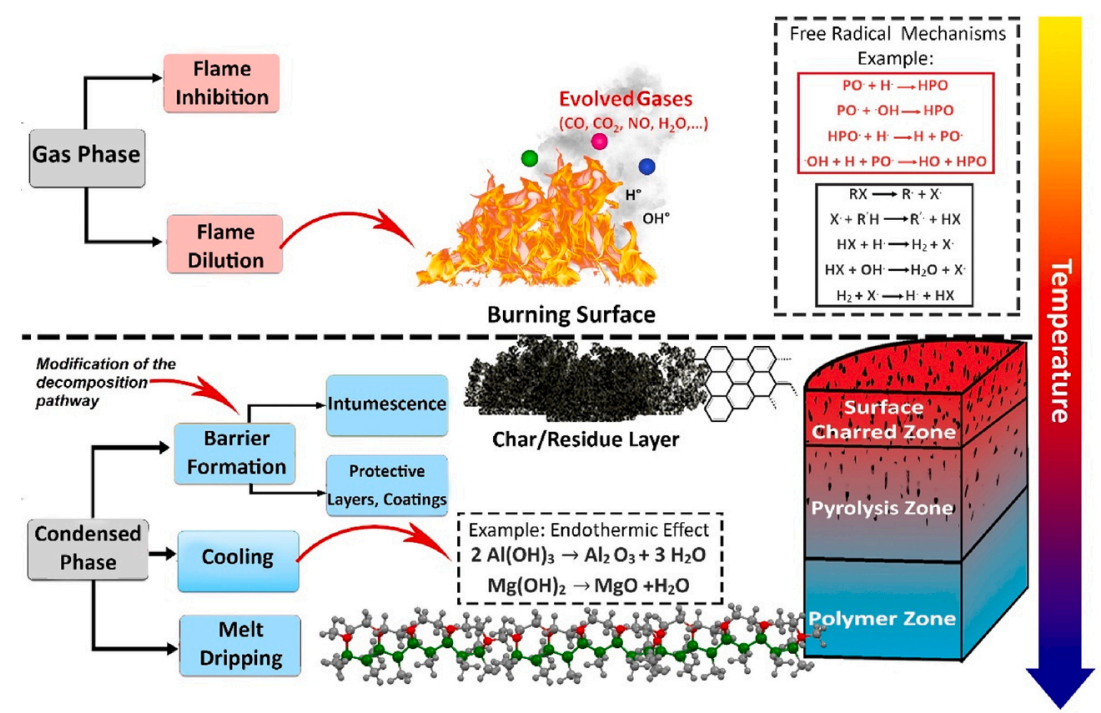

Fig. 6. Possible action mechanisms of flame retardants in the gas and condensed phases.

given flame retardant may perform one, two or three of these actions in one or both phases. The flame retardancy efficiency of the barrier layer formed during combustion varies in function of its nature. Layers can come in different forms such as carbonaceous (char), inorganic, vitreous, ceramic, or intumescent. Overall, their action is more or less similar, consisting in acting as a protective barrier and limiting heat (heat shielding), mass (diffusion barrier), or oxygen transfer between the two phases. Due to these limitations, the rate of thermal decomposition of the polymer, the quantity of combustible gases feeding the flames, and the penetration of oxygen into the polymer are reduced. The process of barrier formation is the result of physical, and/or chemical reactions inside the polymer. The presence of some FRs helps the formation of polyaromatic structures and intermolecular reactions during combustion and therefore the formation of a carbonaceous char. Among the condensed phase solutions, the barrier effect is well-known.

The formation of residue/char during combustion is a crucial point in polymer flame retardancy. It is obvious that the transformation of some of the polymer matrix into residue/char during combustion reduces the amount of fuel released for the combustion process. Furthermore, the presence of residue/char on the surface of polymer may insulate and protect the underlying polymer from the flame. It can slow down the transfer of gases from the pyrolysis zone to the flame and act as a barrier for oxygen penetration from the surface into the condensed phase during combustion. The efficiency of a residue/char layer as a barrier during combustion depends on both its physical and chemical properties. It has been revealed that some quality-related parameters of a given residue/ char are important and can affect flame retardancy. These qualities are usually related to some properties of the residue/char formed during combustion, such as porosity, cohesion, thermal stability, thermal conductivity, hardness, and thickness. It is important to mention that char is the residue of the incomplete combustion of organic material $[6,87]$. It can also be referred to as char residue or carbonaceous residue. However, there is a difference between char and the inorganic residue remaining after thermal decomposition of mineral FRs, such as ATH and $\mathrm{MDH}$, as well as the residue remaining after thermal decomposition of some inorganic polymers such as silicones. It is worth mentioning that "intumescent" char is a special char obtained during the combustion of intumescent flame-retardant systems, generally a carbonaceous residue. In the case of an intumescent protective barrier, the expansion of a protective layer with low thermal conductivity on the surface of polymer limits heat transfer towards the material. Such systems are generally obtained by combining a carbon source agent, generally a polyol, a source of acid which leads to dehydration of the carbon agent, and a swelling agent which, with increased temperature, releases a non-combustible gaseous mixture causing the carbonaceous layer present on the surface of the material to expand.

The cooling action occurs when the thermal decomposition of the flame retardant is an endothermic reaction. Some of the energy inside the material is therefore absorbed, reducing the temperature in the condensed phase. Melt dripping consists in facilitating the dripping of the molten polymer by acting on its rheology, reducing the viscosity of the polymer and separating it from the flame zone.

In the gas phase, two types of flame-retardant action can be obtained. First, the release of inert gases inside the flame during combustion can dilute combustible gases. Second, the radicals formed from the decomposition of the flame retardant trap highly energetic radicals and inhibit fire propagation.

After this brief survey of flame-retardancy mechanisms in polymer materials, it should be borne in mind that potential FRs need to be checked to match any given polymer. In addition, a comprehensive overview of testing procedures is required to thoroughly investigate the mechanistic explanation of flame retardancy in polymer materials.

There are several tests that help to assess flammability/fire performance behavior as a function of heat release, ignitability, flame spread, toxicity/corrosivity, smoke production, and fire resistance. These tests can be classified by sector of activity (aviation, railway, cables, etc.), by industry standards (ASTM, EN, ISO, etc.), or simply be the scale of measurement (small-, bench-, and large-scale tests). Some of these tests are presented in Fig. 7 including LOI, UL-94, pyrolysis combustion flow calorimetry (PCFC), cone calorimetry, panel tests, single burning item (SBI), single-flame source, flame spread tests $[88,89]$. Some other characterization techniques are specifically used to elucidate the mechanism of action of FRs in the gas and/or condensed phase. In addition to these tests, the characterization of char, mineral residue and intumescent char are useful, but quite often challenging because of their complex chemical and physical structure. Furthermore, their homogeneity and the choice of zone analyzed (top, middle, or bottom of remaining residue, Fig. 6) can be crucial.

Cone calorimetry, recognized as the best test for analyzing the fire behavior of polymers, is based on monitoring the oxygen consumption [90] when a polymer sample is irradiated by constant heat flux. The main characteristics measured in this test include the pHRR $\left(\mathrm{kW} / \mathrm{m}^{2}\right)$, THR $\left(\mathrm{kJ} / \mathrm{m}^{2}\right)$, TTI (s), the quantity of $\mathrm{CO}$ and $\mathrm{CO}_{2}$, and the opacity of the smoke in the exhaust duct.

The classification of polymer materials based on flame retardancy has been frequently performed in terms of cone calorimetry data, with 


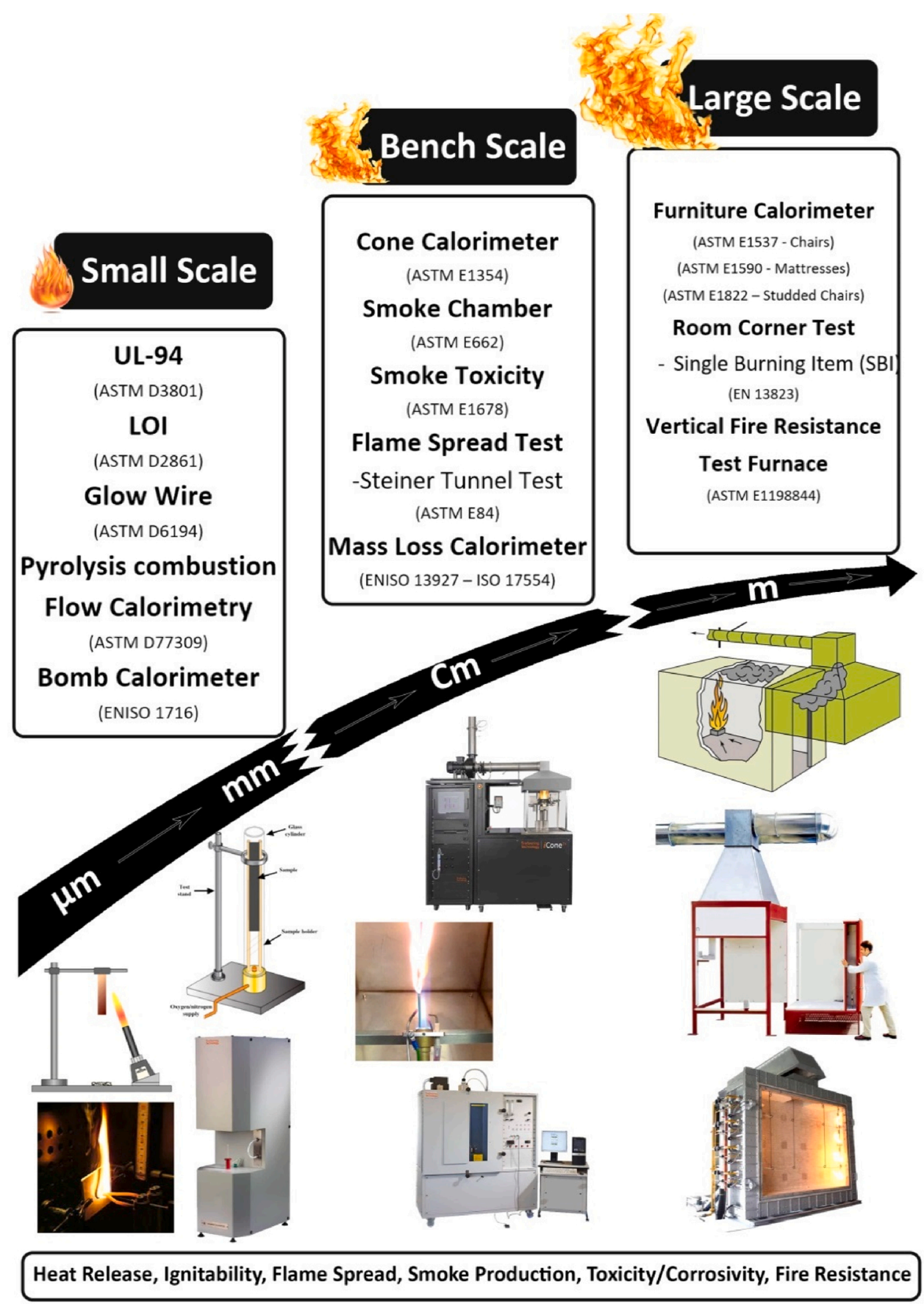

Fig. 7. Various analytic tests commonly used in determining the flame retardancy of polymers, non-exhaustive list.

flame retardant type and content as the main variables [35]. On the other hand, no comprehensive framework has been proposed for classifying flame-retardant polymers based on the efficiency/superiority of flame-retardant additives.

In polymer materials, the addition of two or more flame-retardant additives will not necessarily meet fire protection requirements. For example, polymer materials based on PLA containing $2 \mathrm{wt}$ \% azo-boron modified reduced graphene oxide (GO) intercalated by sodium metaborate hybrid proved highly efficient [91], while PLA filled with $20 \mathrm{wt} . \%$ of aluminum diethylphosphinate/methyl tallow bis (2-hydroxyethyl) ammonium modified montmorillonite showed very low flame retardancy [92]. EVA containing $0.5 \mathrm{wt} . \%$ reduced GO-poly (piperazine spirocyclic pentaerythritol bisphosphonate) revealed a flame retardancy performance almost equal to that of EVA containing
50 wt.\% magnesium hydroxide/graphene [93,94]. The type, state of dispersion, and size of FR additives, as well as their interaction with the polymer during combustion are key-parameters and can modify flame retardancy. It has been reported that the addition of $2 \mathrm{wt} . \%$ polyphosphazene-functionalized black phosphorus nanosheets to an epoxy resin greatly improved flame retardancy, as marked by a considerable drop in the pHRR value of this flame retardant epoxy [95], while $50 \mathrm{wt} . \%$ expandable graphite had no significant effect on the same epoxy resin [96]. Curing was found to play a key-role in this regard [97]. In the light of the above discussion, high quantities of additives do not necessarily lead to a high level of fire protection. To evaluate the flame retardancy performance of classified polymer composites, there is a need for a universal measure for assessing flame retardancy behavior irrespective of the type of polymer matrix, and the type of additive and 
its interaction with the polymer matrix.

Even though cone calorimetry gives useful information about the fire behavior of flame-retardant polymers, the multiplicity of characteristics obtained from this test blurs the evaluation of their flame retardancy and the efficiency of flame retardants. Therefore, understanding the flameretardant efficiency of additives or the fire performance of polymer materials requires the use of some useful criteria providing a complete image of flame retardancy by taking into account all the possible characteristics of cone calorimetry. To date, several indices have been defined and used to explain the flame retardancy performance of polymer materials [98]. In cone calorimetry, the fire scenario can be recognized to some extent from the shape of the plot of HRR against time [99]. Parametrically, pHRR, TTI, THR, smoke quantity, density, and char/residue yield are the main characteristics determining the performance of additives in a polymer [90,99]. Quite frequently, the pHRR, TTI, and THR have been considered as the key parameters of cone calorimetry for the analysis of flame retardancy performance of polymer materials. Certainly, the longer the TTI, the higher the flame retardancy, while lower THR and pHRR values are characteristic of improved flame retardancy. Taking into account that the majority of researches use the aforementioned parameters in their analyses, there have been two strategies that researchers and engineers both use for analyzing the flame retardancy performance of polymer materials based on cone calorimetry data. The first strategy, which has been mainly used by almost all researchers, uses the characteristics obtained from cone calorimetry independently and compares them between the neat polymer and its corresponding composite. For example, the TTI, pHRR and/or THR of a composite can be compared with those of the neat polymer. In such cases, the investigator tends to stress the superiority of the characteristic that was found to show the greatest improvement (TTI, THR or PHRR). Suppose (Case A) that the TTI improved from $30 \mathrm{~s}$ for the neat polymer to $90 \mathrm{~s}$ for the FR polymer composite, while pHRR decreased from $700 \mathrm{~kW} \mathrm{~m}^{-2}$ for the neat polymer to $695 \mathrm{~kW} \mathrm{~m}^{-2}$ for the composite. Contrastingly, suppose (Case B) a slight increase in TTI $30 \mathrm{~s}$ for the neat polymer to $35 \mathrm{~s}$ for the polymer composite, with a drastic drop in the pHRR from $700 \mathrm{~kW} \mathrm{~m}^{-2}$ for the neat polymer to $250 \mathrm{~kW} \mathrm{~m}^{-2}$ for the hypothetical composite. By comparing these cases and regardless of the THR, the researcher who carried out Case A inevitably emphasizes the significant rise observed in the TTI, as a result of using a good flame retardant. By contrast, the researcher who did the experiments in Case B would definitely be expected to highlight the considerable drop observed in the pHRR. This simple example reveals the inadequacy and lack of precision and reliability of such a viewpoint for assessing the efficiency of flame retardant in a given polymer.

The second strategy for analyzing the performance of flameretardant polymers when exposed to fire is to use some indices that have different dimensions, defined by different research groups. For example, fire growth rate (FIGRA), calculated by dividing pHRR by TTI, was introduced as an index [100]. Moreover, the maximum average rate of heat emission (MAHRE) was defined as the ratio of pHRR divided by the time [101]. Based on the definition of indices and parameters used in formulas, low values of these indices should indicate good flame retardancy and fire performance. The aim is to obtain a deeper understanding of flame retardancy by eliminating the confusion engendered by the first strategy, exemplified in Cases A and B. For instance, the FIGRA for the neat polymer of Cases A and B would become 23.34, while for the composites in Case A and Case B it would be 7.73 and 7.14, respectively. Therefore, the use of the FIGRA index reveals that the performances of the additives used in case A and case B are more or less the same. In the aforementioned cases, we assume that the neat polymer is fixed, and when trying to find the best polymer composite among possible candidates; both polymer and additive need to be carefully considered. Suppose we have PLA and EVA, two polymers commonly used in flame retardancy investigations. In such cases, the flame retardancy of the polymer matrix also needs to be considered; therefore, comparison between the behaviors of different systems is not easily achieved. Moreover, the classification of polymers in terms of flame retardancy requires defining some comprehensive indices by taking into account the physical properties as well as the chemical properties of polymer and additives. Moreover, the unexplored nature of the interaction between additive and polymer makes the analysis readily difficult. Further issues include the difficulty of estimating the flame retardancy behavior of thermoset composites due to the dependency of their properties on the crosslinking state of the resin in the presence of additives. Thus, there is a need to use an inclusive index so as to take into account similar behaviors of flame retardant polymers by normalizing their behavior with respect to the neat polymer.

The newly introduced, namely the third, strategy [102,103], uses a universal criterion as a practical measure of the efficiency of flame-retardant additives in polymers. The Flame Retardancy Index (FRI) is a dimensionless index, which takes into account pHRR, THR, and TTI as the main cone calorimetry characteristics. The FRI was defined as the dimensionless ratio between the terms THR* $\left(\frac{\mathrm{pHRR}}{\mathrm{TTI}}\right)$, with the nominator term corresponding to the neat polymer, and the denominator term to the polymer composite [102]:

FRI $=\frac{\left[\text { THR } *\left(\frac{\mathrm{pHRR}}{\mathrm{TTI}}\right)\right]_{\text {Neat Polymer }}}{\left[\mathrm{THR} *\left(\frac{\mathrm{pHRR}}{\mathrm{TTI}}\right)\right]_{\text {Composite }}}$

If the additive works effectively as a flame retardant, the value of the THR* $\left(\frac{\mathrm{pHRR}}{\mathrm{TTI}}\right)$ takes lower values for the polymer composite. Therefore, higher values of FRI are indicative of the effective action of flameretardant additive in the polymer composites. As a simple measure of flame retardancy performance, dimensionless FRI values higher than one are indicative of positive actions of additives in the system. The superiority of the FRI index over the FIGRA and MAHRE indices encountered in the second strategy for comparing the actions of additives can be recognized in its ability to assess the performance of additives irrespective of the type of polymer or the composite. When using the dimensionless FRI, the flame retardancy performance of the polymer composite will be normalized with respect to that of the neat polymer. The additional superiority of the FRI over the FIGRA and MAHRE indices is that the use of FRI makes it possible to classify polymer composites in terms of flame retardancy performance, regardless of the type of polymer matrix and the quantity of additives. The flame retardancy of polymer composites can be qualitatively expressed using the FRI, with three possible cases, 'Poor', 'Good', and 'Excellent', defined on a logarithmic scale. As an example, Table 2 summarizes cone calorimetry data on the TTI (s), pHHR $\left(\mathrm{kW} \mathrm{m}^{-2}\right)$ and THR ( $\mathrm{MJ} \mathrm{m}^{-2}$ ) for a number of reports on PA6 composites varying the type and amount of additives. In this table, the values of the FRI for the PA6 composites are calculated using Eq. (1). Fig. 8 visualizes the variation of the FRI as a function of wt. $\%$ of additives used in PA6 composites.

Three cases of flame retardancy performance rated as Poor, Good, and Excellent are specified in Fig. 8. As described earlier, the lower limit for the performance of a given flame-retardant additive in a given polymer matrix would be specified by FRI value of 1 , below which additives have a negative effect on the resistance of polymer against flame. Therefore, FRI values below $10^{\circ}(\mathrm{FRI}<1)$ are characteristic of polymer composites with Poor flame retardancy performances. In the case when $10^{\circ}<\mathrm{FRI}<10^{1}$, the flame retardant is considered to have a "Good" effect on the polymer. It is easy to see how the FRI values change in the assigned interval depending on the nature of the additive and its composition. There is another region based on the logarithmic scale, FRI $<10^{1}$, which is nominated as the "Excellent" flame retardancy zone. Practically, a combination of strong FRs, which are typically known for their actions in both the gas and condensed phase, used at high loadings may lead to an "Excellent" case. The use of the FRI criterion proved 
Table 2

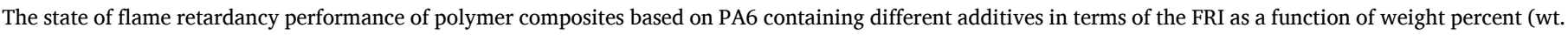
$\%)$. The names of incorporated additives are given in the table with symbols demonstrating their family.

\begin{tabular}{|c|c|c|c|c|c|c|c|}
\hline & Polymers and incorporated additives* & $\begin{array}{l}\text { wt. } \\
\%\end{array}$ & $\begin{array}{l}\text { TTI } \\
(s)\end{array}$ & $\begin{array}{l}\text { pHRR } \\
(\mathrm{kW} . \\
\left.\mathrm{m}^{-2}\right)\end{array}$ & $\begin{array}{l}\text { THR } \\
\text { (MJ. } \\
\mathrm{m}^{-2} \text { ) }\end{array}$ & FRI & Ref. \\
\hline & Polyamide 6 (PA6) & 0 & 74.8 & 1021.8 & 127.6 & - & [104] \\
\hline - & Interdigitated crystalline montmorillonite-melamine cyanurate (MC-MMT) & 8 & 74.5 & 844.4 & 126.5 & 1.21 & [104] \\
\hline \multirow[t]{2}{*}{$\overline{\mathbf{a}}$} & Melamine cyanurate/organically modified montmorillonite (MC/OMMT) & 8 & 63.3 & 711.8 & 122.9 & 1.26 & [104] \\
\hline & PA6 & 0 & 61 & 921.6 & 174.8 & - & [105] \\
\hline - & Octodecyltrimethylammonium bromide modified layered montmorillonite (OTAB-MMT) & 6 & 92 & 348.6 & 167.5 & 4.16 & [105] \\
\hline 0 & $\begin{array}{l}\text { Aluminum diisobutylphosphinate/octodecyltrimethylammonium bromide modified layered montmorillonite } \\
\text { (APBA/OTAB-MMT) }\end{array}$ & 12 & 92 & 315.1 & 137.4 & 5.61 & [105] \\
\hline - & АРВА/OTAB-MMT & 12 & 124 & 293.8 & 141.7 & 7.86 & [105] \\
\hline - & АРВA/OTAB-MMT & 12 & 81 & 288.5 & 144.3 & 5.13 & [105] \\
\hline \multirow[t]{2}{*}{ - } & APBA/OTAB-MMT & 12 & 81 & 263.2 & 147.4 & 5.51 & [105] \\
\hline & PA6 & 0 & 64 & 1227 & 99 & - & [106] \\
\hline$\Delta$ & Montmorillonite (MMT) & 3 & 84 & 681 & 96 & 2.43 & [106] \\
\hline$\Delta$ & Montmorillonite/disodium H-phosphonate (MMT/DHP) & 3.75 & 76 & 770 & 99 & 1.89 & [106] \\
\hline$\Delta$ & (dimethyl benzylhydrogenated tallow ammonium) salt modified Montmorillonite (D43B) & 3 & 92 & 660 & 94 & 2.81 & [106] \\
\hline \multirow[t]{2}{*}{$\Delta$} & $\begin{array}{l}\text { (dimethyl benzylhydrogenated tallow ammonium) salt modified Montmorillonite/disodium H-phosphonate } \\
\text { (D43B/DHP) }\end{array}$ & 3.75 & 78 & 579 & 89 & 2.87 & [106] \\
\hline & PA6 & 0 & 96 & 1055 & 171 & - & [107] \\
\hline$\nabla$ & Methyltallow bis-2-hydroxyethyl quaternary ammonium modified Montmorllonite (C30B) & 5 & 106 & 473 & 169 & 2.49 & [107] \\
\hline$\nabla$ & $\begin{array}{l}\text { Aluminum diethylphosphinate/methyltallow bis-2-hydroxyethyl quaternary ammonium modified Montmorllonite } \\
\text { (OP/C30B) }\end{array}$ & 20 & 77 & 372 & 147 & 2.64 & [107] \\
\hline \multirow[t]{2}{*}{$\nabla$} & $\begin{array}{l}\text { Aluminum diethylphosphinate/zinc borate/methyltallow bis-2 hydroxyethyl quaternary ammonium modified } \\
\text { Montmorllonite (OP/ZB/C30B) }\end{array}$ & 20 & 89 & 295 & 139 & 4.07 & [107] \\
\hline & PA6 & 0 & 91 & 1097 & 85 & - & [108] \\
\hline$\bullet$ & $\begin{array}{l}\text { Ammonium sulphamate/dipentaerythritol/dimethyl, n-hexyl, hydrogenated tallow quaternary ammonium } \\
\text { sulphate modified montmorillonite (AS/DPER/C25A) }\end{array}$ & 4.5 & 80 & 953 & 81 & 1.06 & [108] \\
\hline$\bullet$ & AS/DPER/C25A & 5.5 & 75 & 881 & 79 & 1.1 & [108] \\
\hline$\bullet$ & $\begin{array}{l}\text { Ammonium sulphamate/dipentaerythritol/methyl, tallow, bis-2-hydroxyethyl, quaternary ammonium chloride } \\
\text { modified montmorillonite (AS/DPER/C30B) }\end{array}$ & 4.5 & 73 & 998 & 81 & 0.92 & [108] \\
\hline$\bullet$ & AS/DPER/C30B & 5.5 & 67 & 832 & 72 & 1.14 & [108] \\
\hline$\bullet$ & Ammonium sulphamate/dipentaerythritol/Bentonite (AS/DPER/BT) & 4.5 & 73 & 936 & 80 & 0.99 & [108] \\
\hline \multirow[t]{2}{*}{ 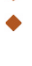 } & AS/DPER/BT & 5.5 & 77 & 912 & 79 & 1.09 & [108] \\
\hline & PA6 & 0 & 141 & 1034 & 87.9 & - & [109] \\
\hline 4 & Methyl bis-(2-hydroxyethyl) tallow ammonium modified montmorillonite (C30B) & 5 & 117 & 444 & 82.6 & 2.05 & [109] \\
\hline 4 & $\begin{array}{l}\text { Aluminium diethyl phosphinate/methyl bis-(2-hydroxyethyl) tallow ammonium modified montmorillonite (OP/ } \\
\text { C30B) }\end{array}$ & 20 & 140 & 232 & 63 & 6.17 & [109] \\
\hline 4 & $\begin{array}{l}\text { Aluminium diethyl phosphinate/Pentaerythritol/methyl bis-(2-hydroxyethyl) tallow ammonium modified } \\
\text { montmorillonite (OP/PER/C30B) }\end{array}$ & 20 & 144 & 366 & 66.9 & 3.79 & [109] \\
\hline 4 & Ammonium polyphosphate/methyl bis-(2-hydroxyethyl) tallow ammonium modified montmorillonite (APP/C30B) & 20 & 60 & 420 & 71.4 & 1.28 & [109] \\
\hline \multirow[t]{2}{*}{4} & $\begin{array}{l}\text { Ammonium polyphosphate/Pentaerythritol/methyl bis-(2-hydroxyethyl) tallow ammonium modified } \\
\text { montmorillonite (APP/PER/C30B) }\end{array}$ & 20 & 79 & 491 & 76.8 & 1.35 & [109] \\
\hline & PA6 & 0 & 70 & 1434 & 148.1 & - & [110] \\
\hline - & Graphene nanosheet (GN) & 2 & 79 & 1257 & 133.1 & 1.43 & [110] \\
\hline $\bar{\square}$ & Graphene nanosheets coated with Cobalt oxide $\left(\mathrm{Co}_{3} \mathrm{O}_{4}-\mathrm{GN}\right)$ & 2 & 81 & 1282 & 141.4 & 1.35 & [110] \\
\hline \multirow[t]{2}{*}{ 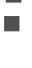 } & Graphene nanosheets coated with Nickel oxide (NiO-GN) & 2 & 75 & 1105 & 130 & 1.58 & [110] \\
\hline & PA6 & 0 & 157 & 727 & 93 & - & [111] \\
\hline \multirow[t]{2}{*}{ - } & Multi-walled carbon nanotube (MWCNT) & 5 & 189 & 414 & 90 & 2.18 & [111] \\
\hline & PA6 & 0 & 47 & 977 & 83 & - & [111] \\
\hline \multirow[t]{2}{*}{$\Delta$} & MWCNT & 5 & 56 & 768 & 98 & 1.28 & [111] \\
\hline & PA6 & 0 & 32 & 1136 & 97 & - & [111] \\
\hline \multirow[t]{2}{*}{$\nabla$} & MWCNT & 5 & 32 & 1136 & 97 & 1 & [111] \\
\hline & PA6 & 0 & 91 & 1097 & 85 & - & [111] \\
\hline $\mathbf{\square}$ & Ammonium sulphamate/Dipentaerythritol/Fumed Silicon dioxide (AS/DPER/ $\mathrm{fSiO}_{2}$ ) & 4.5 & 78 & 1041 & 79 & 0.97 & [111] \\
\hline \multirow[t]{2}{*}{ 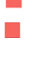 } & $\mathrm{AS} / \mathrm{DPER} / \mathrm{fSiO}_{2}$ & 5.5 & 84 & 862 & 78 & 1.28 & [111] \\
\hline & PA6 & 0 & 191 & 678 & 123 & - & [112] \\
\hline - & Silicon dioxide modified melamine cyanurate/Pentaerythritol $\left(\mathrm{SiO}_{2}-\mathrm{MC} / \mathrm{PER}\right)$ & 7 & 292 & 667 & 97 & 1.97 & [112] \\
\hline - & $\mathrm{SiO}_{2}-\mathrm{MC} / \mathrm{PER}$ & 10 & 240 & 557 & 90 & 2.09 & [112] \\
\hline - & $\mathrm{SiO}_{2}-\mathrm{MC} / \mathrm{PER}$ & 12 & 224 & 402 & 73 & 3.33 & [112] \\
\hline
\end{tabular}

successful in the classification of epoxy-based thermoset composites containing different sorts of additives [103]. It also elucidated the synergistic effects of phosphorus and mineral flame-retardant additives in the case of EVA thermoplastic composites [113]. FRI variation was also shown to correlate correctly to the state of curing in epoxy-based nanocomposites [114].

\section{3D printing of polymer materials}

Developing high-performance flame-retardant polymer materials requires both advanced materials and processing. Nevertheless, reports on processing and manufacturing methods applied in developing flame retaradant polymers are limited. Development of the next generation of flame retardant polymer materials for advanced applications requires the knowledge of processing, new tools and modern strategies. Additive manufacturing (AM) or three-dimensional (3D) printing is a common and highly flexible technique for producing complex shapes using various materials types $[115,116]$. It is growing rapidly due to the numerous advantages it presents compared to conventional machining, e.g. faster production, lower material, and energy waste, and the possibility of creating complex-shaped products $[117,118]$. Among printable materials, polymers have been widely used in AM for their facile 
processability and reasonable cost [119-121]. Another advantage of selecting polymers for this technology is their high diversity and adaptability to various 3D printing machines [22,122,123]. Polymer materials can be applied in various domains such as aerospace, medical tools, toy manufacturing, and architecture [124-127] and different forms including powder, resin, filaments, and reactive monomers [128-130]. As shown in Fig. 9, polymers have been used in more than half of AM-based products due to their lower density and cost, making them an ideal option for the manufacturing of complex designs with many applications. Fig. 10 categorizes the AM processes of polymers in terms of the material, pattern, and printing technology.

\subsection{Stereolithography (SLA) and digital light processing (DLP)}

Stereolithography (SLA) can create a part or product through layer by layer fabrication using a photochemical process. A UV laser links the chemical monomers together along the desired path to polymerize the photocurable resin and create a 2D patterned layer. Then, the platform moves down to make another layer, and finally, the whole object, as shown in Fig. 11 [24,133,134]. Acrylic and epoxy resins are typical polymer materials employed in the SLA process. Controlling the printing parameters (e.g. laser power, duration, scan speed) and consequently, the polymerization process can directly affect the quality and resolution of the final 3D printed parts $[135,136]$. Moreover, UV absorbers and photoinitiators can be applied in the process to adjust the depth to which polymerization can be continued $[137,138]$. Overall, the principal benefit of SLA technology lies in the high quality of the printed parts, and that it is nozzle-free. However, the high cost of the machine is considered as the main issue for industrial companies [24].

Similar to SLA technology, Digital Light Processing (DLP) uses light to build a product in the photo-resin layer by layer. However, in DLP each layer is built all at once, while the layers are created point by point in the SLA process [139]. The DLP process dynamically creates the printed material layer by layer as black and white pictures based on photolithography [140]. With this technology, the printing time is significantly shorter than that of the SLA process. Moreover, the polymerization process is carried out under the vat method; therefore, there is no direct contact with atmospheric oxygen, improving the quality of DLP fabricated products compared to those obtained through the SLA. Fig. 12 shows a diagram of the DLP process including various parts of the system [141].

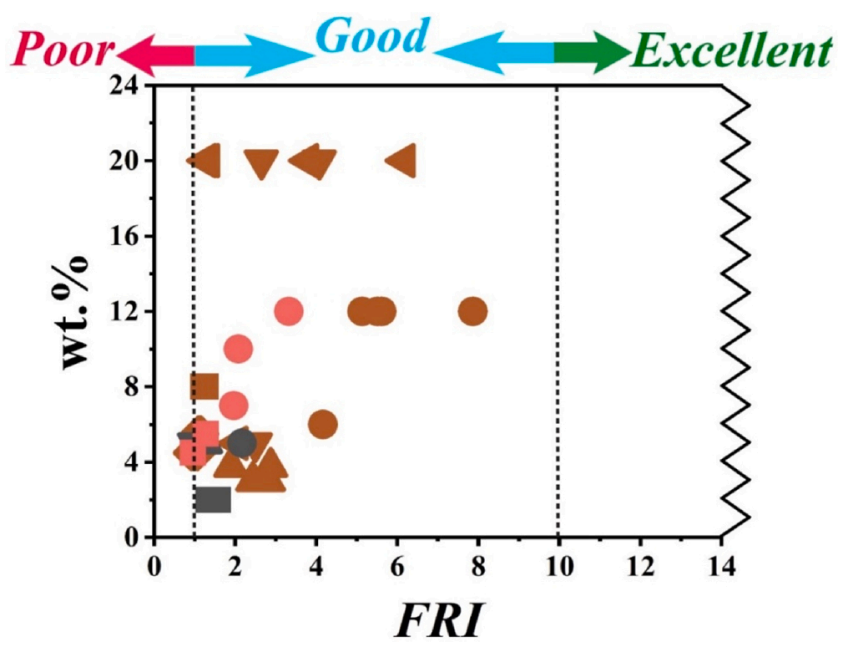

Fig. 8. Variation in FRI for PA6 polymer composites containing mineral, carbon-based and metal oxide nanoparticles as a function of weight percent (wt. $\%)$. Colored symbols are indicative of the category of the nanoparticles.

\subsection{MultiJet/PolyJet 3D printing}

MultiJet/PolyJet is an advanced inkjet technology that uses several printing nozzles for precisely spraying small droplets of photopolymers or liquid materials point by point. In this process, UV light creates a thin layer on the platform and the process is repeated to form a 3D object. The basic setup of the PolyJet process is illustrated in Fig. 13 [122]. The injection head typically deposits two different materials, for building and support. The printed support is not a part of the final object and needs to be removed after the fabrication process. This aspect makes the MultiJet/PolyJet technique less economical compared to SLA. However, the material jetting process has some advantages such as the fabrication of high-resolution products with good surface characteristics using simultaneous multi-material printing. It can also provide the user with large build volume and high build speed production. Moreover, it enables multi-color materials to be chosen for printing the final product $[131,132,142]$.

\subsection{Selective laser sintering (SLS) $3 D$ printing}

SLS is another printing process applicable to polymers based on powdered materials. A laser scan on the powder bed creates the final object layer by layer in the form of a 3D structure. Fig. 14 shows a diagram of the SLS setup including various components [143]. The laser beam directly fuses the exposed particles in the form of a 2D design and the build cylinder moves downward (in the z-direction) in function of the desired layer thickness, and another layer is fabricated on top of the previously printed (scanned) layer. This process continues until the final $3 \mathrm{D}$ object is created. To prevent any damage or distortion to the printed object, the polymer powders are preheated to close to their melting temperature before the printing process [132,144].

The SLS process can be applied for various types of materials such as polymers [145-148], metals [149,150], and ceramics [151]. The main polymers used in the SLS process are PA [152-154], poly( $\varepsilon$-caprolactam) (PCLa) [155], and other semi-crystalline thermoplastics like polyethylene (PE) [156], PEEK [157]. In more detail, the polymers applicable to the SLS process can be categorized as follows: full melting, liquid phase sintering-partial melting, solid-state sintering (SSS), and chemically induced binding. In the full melting process, the powders melt entirely to make the final printed object [158], whereas the temperature in the SSS thermal process can be between the melting points of the powder $\left(\mathrm{T}_{\text {melt }}\right)$ and $\mathrm{T}_{\text {melt } / 2}$ [159]. The binder material in liquid phase sintering-partial melting can become liquid-like, whereas the skeleton of the material has a solid form. Table 3 categorizes the principle materials applied in the SLS process and their consolidation mechanisms [160].

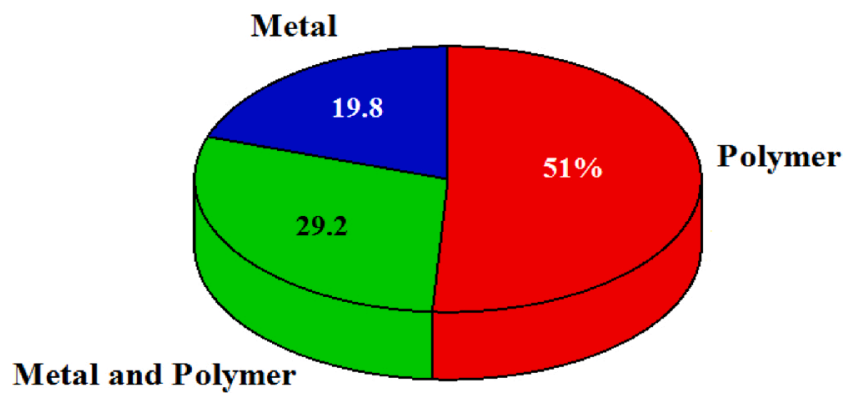

Fig. 9. Parts currently produced by AM technology [131]. It is clear that half of the production volume belongs to polymers. Looking at such a status from flame retaradncy standpoint, the development of flame-retaradnt polymer materials using 3D printing seems to follow a flourishing period in the near future. Since the methods applied in 3D printing of polymers for flame retardant applications are at an early stage of development, it is of vital importance to know all possible ways/methodologies by which polymers can be 3D printed. 


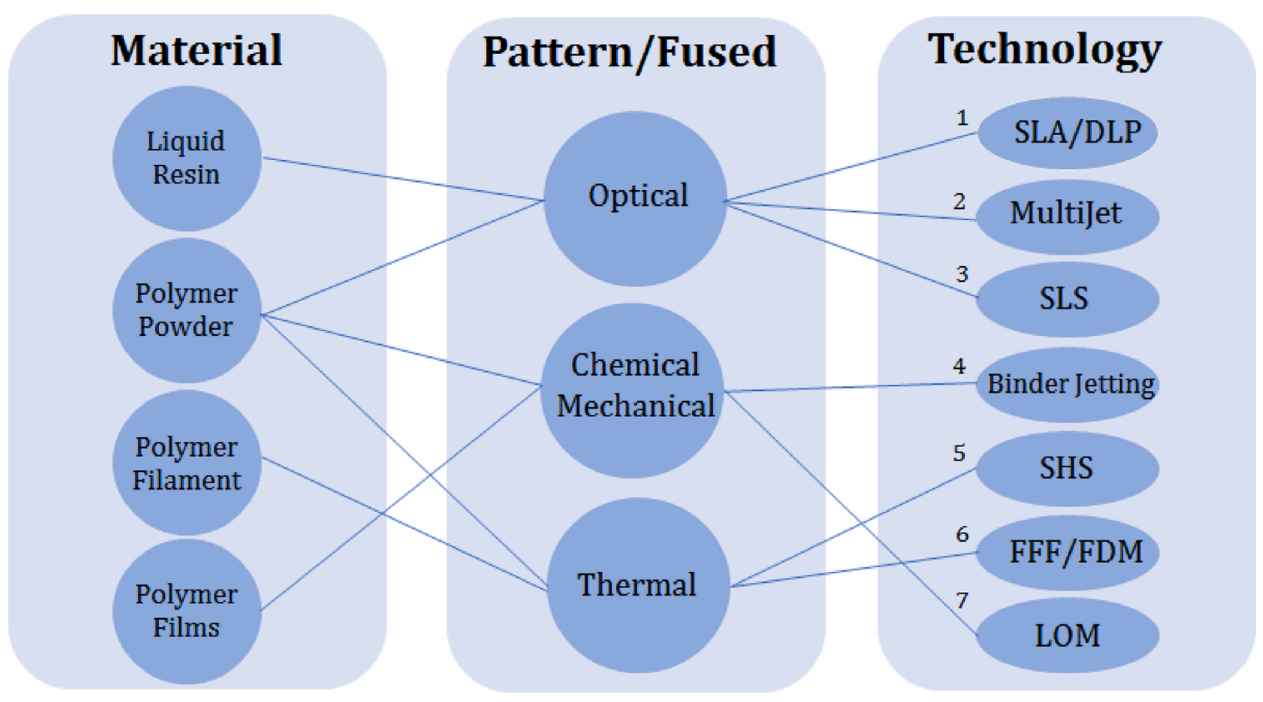

Fig. 10. Polymer-based additive manufacturing (AM) processes [132]. The 3D printing technologies used for polymer AM are Stereolithography (SLA), Digital Light Processing (DLP), PolyJet, Selective Laser Sintering (SLS), Binder Jetting, Selective Heat Sintering (SHS), Fused Filament Fabrication (FFF)/Fused Deposition Modeling (FDM), and Laminated Object Manufacturing (LOM). When thinking of developing 3D printed flame retardant polymers, the illustration seems to be a puzzle to be resolved in the near future, for difficulties in shaping polymers of different families (overall, let's say thermoplastics and thermosets) should be taken into account when 3D printing flame retardant polymers.

\subsection{Binder jetting $3 D$ printing}

In the binder jetting process, a liquid binder is deposited selectively on the surface of the powder bed formed by a print head to connect the particles through chemical reaction or solvent welding. Since there is no thermal process, it improves the quality of the final product. Fig. 15 illustrates how the liquid binding agent can be deposited and join the powder materials in the binder jetting process [161,162].

The powder used can be made from various other materials as well as polymers, and a dilute polymer solution is usually used as a binder. In this process, there are more choices for polymer powder materials than in the SLS process, because there are no constraints such as thermal processes for using a particular powder. The other advantage of this process is its flexibility in applying several print heads, which allows for designing multi-color products with suitable strength and surface finish $[132,163]$.

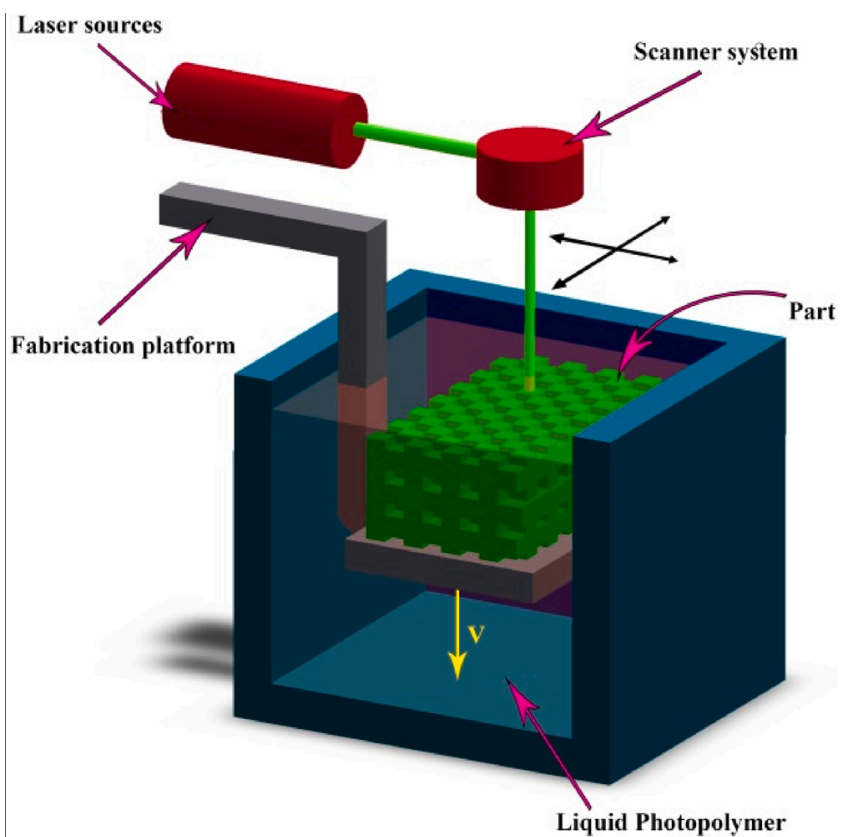

Fig. 11. A diagram of Stereolithography (SLA) technology in top-to-down production form. The UV light creates the final object layer by layer in the photocurable resin bath without using any support structure [24].

\subsection{Selective heat sintering (SHS)}

SHS technology utilizes powder bed fusion for the printing process, similar to SLS but with some major differences. SHS uses a thermal print head to fuse the powder surface, while SLS applies a laser beam instead [132]. Moreover, the SHS technique can be considered as a low-cost process compared to SLS for 3D printing of polymeric objects. Fig. 16 shows a diagram of the SHS process, and how a thin polymer layer can be fabricated by a thermal print head. The printer components include the powder deposition mechanisms and the heaters, which are inside the internal build volume. Once the new surface is built, the print head assembly is detached from the just-built surface by a conductive separation sheet. The sheet is supplied continuously [164].

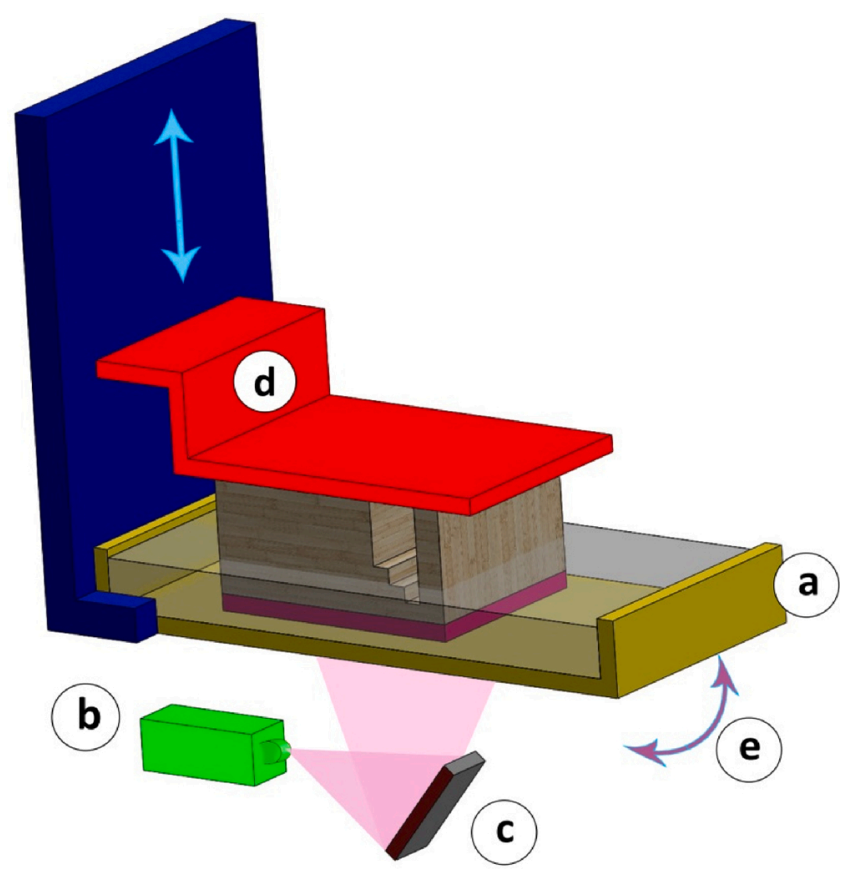

Fig. 12. Diagram of the digital light processing (DLP) process, including (a) vat filled with photopolymer resin, (b) light source, (c) micromirror array, (d) vertically movable building platform, and (e) tilting device to replenish the uncured bottom layer. This is a bottom-to-top building process in which a light source solidifies the photopolymer resin in a continuous production method [141]. 


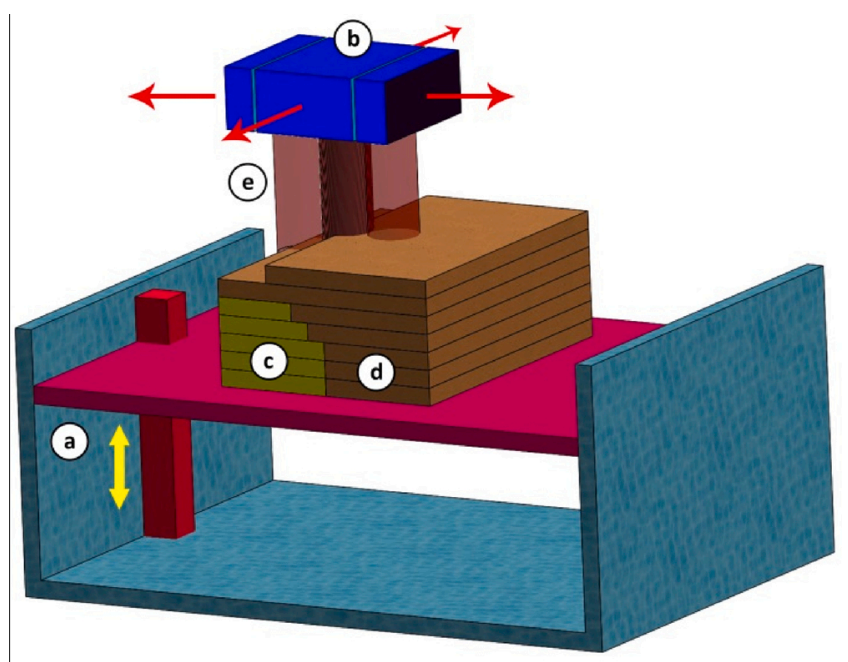

Fig. 13. Diagram of the PolyJet process, including (a) vertically movable building platform, (b) multi-nozzle inkjet head, (c) layers of support material, (d) layers of building material, and (e) UV source attached to inkjet head. In this process, printing heads dispense the droplets of liquids on the platform in order to build an object layer-by-layer using a support structure. [122].

\subsection{Fused deposition modeling (FDM)/fused filament fabrication (FFF)}

FDM/FFF are the two well-known printer techniques used in the fabrication of polymer products. They are usually applied to lowtemperature plastics like polylactic acid (PLA) and acrylonitrile butadiene styrene (ABS), and also PC. Fig. 17 shows a diagram of the FDM printer and its components. It works based on controlled extrusion of polymeric filaments such that the nozzle melts the filaments into a semiliquid material and extrudes layer by layer on the platform to make the final part. The printing parameters, namely printing speed, layer thickness, pattern, raster angle, and width have a direct influence on the quality of the final products and need to be controlled accurately [165].

One of the limitations of this technology is the restriction of filament materials and properties [145]. The other drawback is related to choosing a polymer material with a suitable melt viscosity since it needs to be low enough for the extrusion process but also high enough to provide structural support. However, FDM printers offer some advantages such as low cost, simplicity, and high speed. These aspects make this type of printer a good option to be applied for printing multi-functional designs and products $[166,167]$.

\subsection{Laminated object manufacturing (LOM)}

LOM was one of the first commercially available AM technologies, working on the basis of layer-by-layer cutting of materials in the form of a sheet roll. The layers are cut precisely by laser or mechanical cutter, then bonded together $[128,136]$. Excess materials can be removed and recycled after completion of the process [168]. Fig. 18 shows a diagram of the LOM process and the components [169]. Various materials can be used in the LOM process such as metals, plastics, paper, fabrics, and composites [145]. In LOM, post-production processing can be important depending on the materials and final properties required.

LOM printers can be utilized in several industries such as electronics, paper manufacturing, smart structures, sensors, and processors. The advantage of this process is a reduction in manufacturing time, tool costs, and it is appropriate for manufacturing large structures. Nevertheless, the dimensional accuracy of LOM manufactured parts is not as high as in powder bed technologies. Although the excess parts of printed

Table 3

Consolidation mechanisms versus materials used for the SLS process [160].

\begin{tabular}{lllll}
\hline $\begin{array}{l}\text { Material } \\
\text { types }\end{array}$ & $\begin{array}{l}\text { Solid-state } \\
\text { sintering }\end{array}$ & $\begin{array}{l}\text { Liquid phase } \\
\text { sintering partial } \\
\text { melting }\end{array}$ & $\begin{array}{l}\text { Full } \\
\text { melting }\end{array}$ & Chemical \\
\hline Polymers & No & Yes & $\begin{array}{l}\text { Yes (like } \\
\text { PA) }\end{array}$ & $\begin{array}{l}\text { Seldom (like } \\
\text { partial cross- } \\
\text { linking PMMA) }\end{array}$ \\
Metals & Seldom & Yes & $\begin{array}{l}\text { Yes (like } \\
\text { Ti, SS) } \\
\text { Yes (like SS) }\end{array}$ & Yes (like SiC) \\
Ceramics & Yes & Yes & $\left.\mathrm{ZrO}_{2}\right)$ & Yes (like $\mathrm{Al}_{2} \mathrm{O}_{3^{-}}$ \\
Cermets & No & Yes & Cu) \\
\hline
\end{tabular}

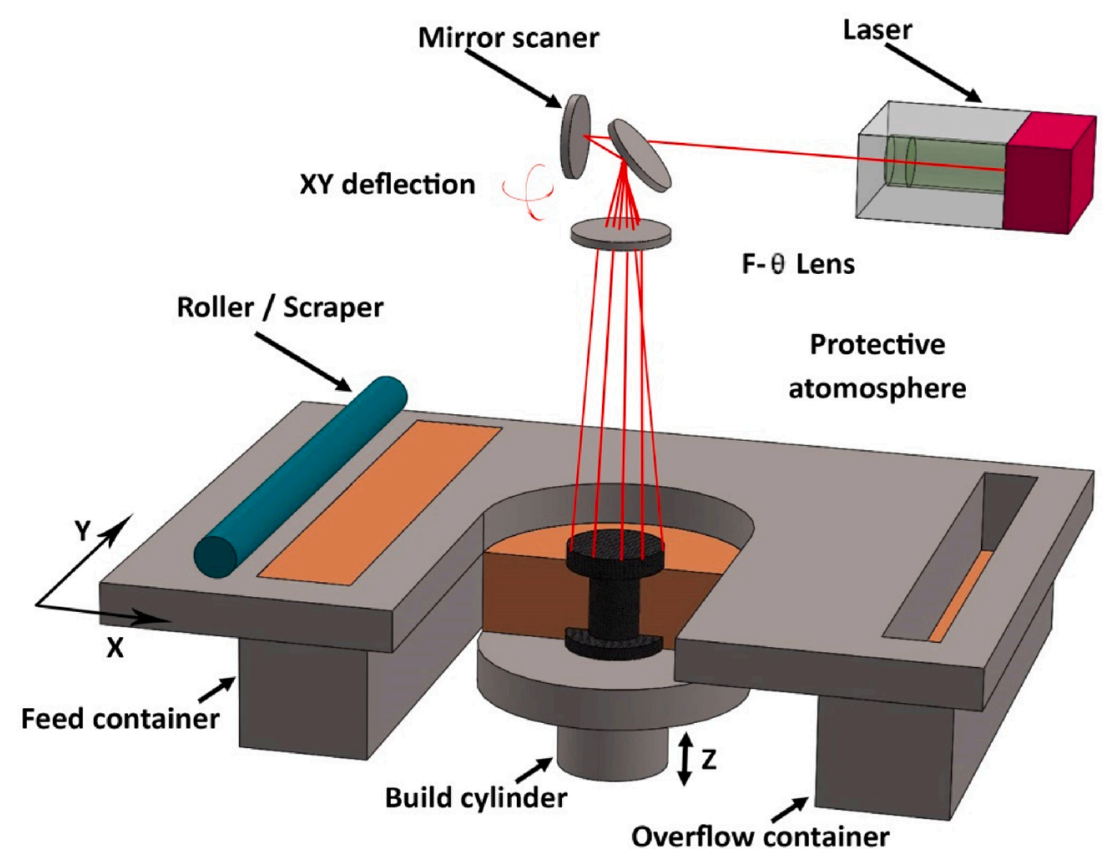

Fig. 14. The Selective Laser Sintering (SLS) method applies laser power to locally fuse the polymer powder on a preheated platform which improves the mechanical and microstructural properties of the fabricated parts [143]. 


\section{Step 1}

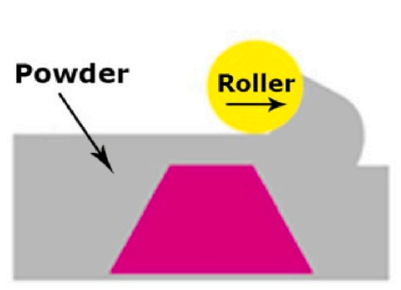

\section{Step 2}

\section{Printhead}

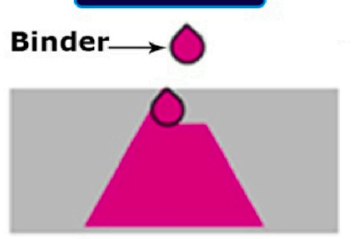

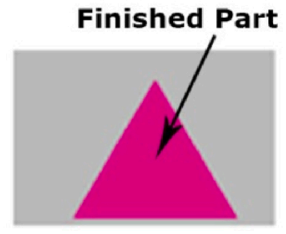

Fig. 15. Diagram of the binder jetting process; the new powder continuously is added to the bed in step 1 , then the print head selectively binds the powder bed using a movable platform in step 2, and, as a result, the finished part can be created [161].

laminates can be recycled, the LOM process is also slower those using the powder bed strategy [128]. Table 4 summarizes a list of AM technologies with some information about the typical resolution and materials, together with the advantages, and limitations of these processes.

\section{3D printing for developing flame-retardant polymers}

Currently, the development of flame-retardant filaments and powders for 3D printing and AM purposes has become a priority for the further expansion of these techniques. In this regard, the type, loading percentage, and dispersion state of the flame retardant(s) have a considerable impact on the rheology of the polymer during the process. Furthermore, to control fire propagation on the surface of structures, the ability to form a multi-layer 3D printed polymer composite is required. This will soon become widespread with the development of new generations of flame-retardant polymer composites with well-controlled fire behavior on the surface of structures. Since there are several techniques for 3D printing thermoplastics and thermosets, approaching 3D printing from the flame retardancy perspective is set to pave the way towards future developments in the design and manufacture of flame-retardant polymer composites.

There are already some flame-retardant printable polymers on the market, Table 5 with the UL-94 test results.

Several issues can be related to the "flame retardancy" and "3D printing" of polymeric materials such as the effect of 3D printing on flame retardancy of polymeric materials in the presence (or not) of flame retardant, processability of flame retardant materials in 3D printing especially with a high percentage of flame retardant, as well as the use of $3 \mathrm{D}$ printing to improve the flame retardancy. The main difficulty of printing polymers containing flame retardants is related to the variation in viscosity and the setting of printing parameters. A survey of the literature showed that various methods have been employed by academic researchers to reduce the flammability or produce the flameretardant printed materials. These strategies can be classified into three main categories by which one would be able to improve the flame retardancy of materials made by AM, Fig. 19. These strategies will be discussed below.

The first strategy is based on the incorporation of conventional FRs into the polymer via melt blending and the fabrication of filaments or pellets, or the preparation of polymer/FR powder, Fig. 19 (a). PLA has been one of the most regularly used polymers in AM. However, PLA is highly flammable which makes its usage difficult for some applications. Several flame retardants have been already reported in the literature as solutions to the flammability of PLA, and today there are some commercially available FR solutions [63]. However, some of these solutions cannot be used in 3D printing because of the particle size and high loading percentage of the flame retardant, which increases the viscosity of polymer and therefore prevents the fabrication of appropriate filaments, pellets, or powder. Guo et al. [184] reported the preparation of flame-retardant PLA samples by 3D printing, rated V-0 in UL-94 tests. The combination of melamine polyphosphate (MPP) at $17 \mathrm{wt} . \%$ and Cloisite 30B (C-30B) at $1 \mathrm{wt} . \%$ has been proposed for preparing printable flame-retardant PLA. The authors showed that the presence of MPP can make the PLA brittle, and thus unsuitable for 3D printing. However, the addition of only $1 \mathrm{wt} . \%$ C-30B led to good ductility of the sample. Moreover, a significant fall in pHRR (around 58 $\%$ ) was observed in cone calorimeter tests, compared with the neat 3D printed PLA. The proposed formulation led to an increase in LOI to 28.5

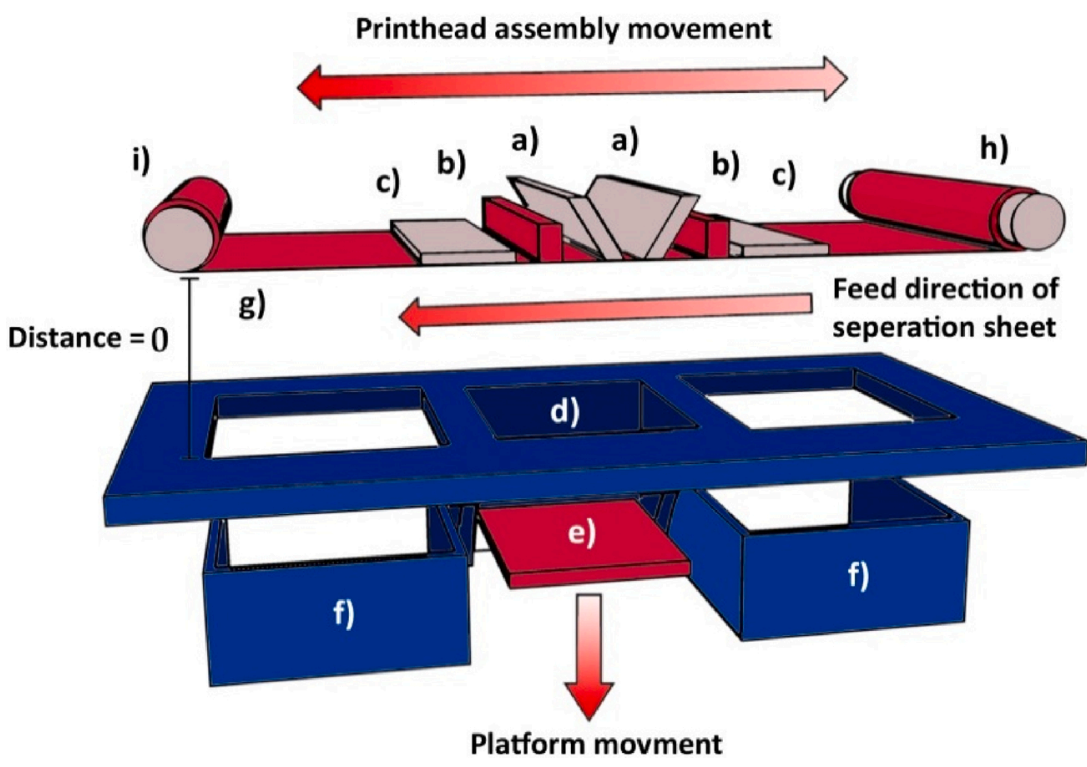

Fig. 16. Schematic illustration of the Selective Heat Sintering (SHS) process [164]. The printer components are (a), powder deposition mechanisms (b), and layer heaters (c). The material is formed in an internal build volume (d), so that the floor of the build platform moves vertically (e). Fresh powder is supplied by the scoops to the powder deposition zone from the powder containers (f). After the new layer is formed, the print head assembly is detached from the build pool by a thermally conductive sheet $(\mathrm{g})$. This sheet spools from a fresh sheet roll (h) to a used sheet roll (i) during the manufacturing process. 


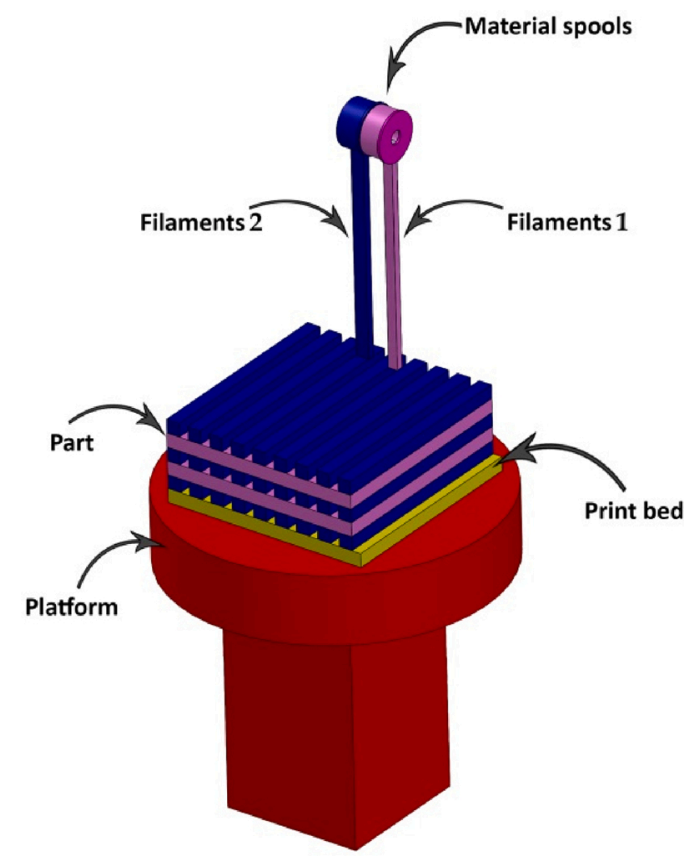

Fig. 17. Fused Deposition Modeling (FDM)/Fused Filament Fabrication (FFF) technology uses one or more nozzle heads that thermally melt the polymeric filaments and build the designed object layer-by-layer. The preheated platform can efficiently increase the adhesion between the primary layers, and consequently improves the quality of the printed object.

as against 20 for neat 3D printed PLA. The authors also compared the flame retardancy of the formulation prepared by 3D printing and injection molding, Fig. 20. Their results revealed similar behavior in samples regardless of processing mode, except for a slight reduction in the TTI for the printed sample, which can be explained by higher porosity arising from the printing process.

Geoffroy et al. [185] fabricated flame-retardant EVA samples printed by an FDM printer using pellets obtained by melt blending EVA with ATH and expandable graphite (EG) in a twin-screw extruder. They also prepared similar formulations by the thermo-compression method. Although the preparation process (3D printing or compression) was shown to induce a slight difference in the mass, density, and thickness of the samples, the flame retardant behavior, evaluated by mass loss calorimetry, was quite similar, except for the EVA/ATH $10 \mathrm{wt} . \%$ sample. The incorporation of $65 \mathrm{wt} . \%$ ATH caused the pHRR to decrease by 78 $\%$, the THR to fall by $49 \%$, and the TTI to increase by $72 \%$, compared with neat EVA. The significant reduction in PHRR is related to the high loading percentage of filler. Nevertheless, this study showed that it is possible to have a high loading percentage of additives to achieve a flame retardant material via 3D printing. For the composite containing ATH $10 \mathrm{wt} . \%$, the fire behavior was worse in 3D printed samples, which was explained by the smaller size of EG after 3D printing, higher porosity in the 3D printed samples, and the anisotropy of material due to preferential orientation of EG particles during 3D printing. It was concluded that these factors led to variations in the physical barrier, and also thermal conductivity, and therefore to the difference in fire behavior between 3D-printed and molded samples.

A quite different strategy has been proposed by Kolibaba et al. [186]. The authors used a polyelectrolyte complex (PEC), a mixture of a polycation and a polyanion, as an additive instead of conventional FRs. In this study, a plasticized PEC of polyvinylamine (PVA) and sodium polyphosphate (PSP), Fig. 21, was synthesized and melt blended with PLA at $25 \mathrm{wt} . \%$ of loading through the extrusion process. Then, the prepared filaments were used for printing in a commercial FFF 3D printer. Thermogravimetric analysis (TGA) showed a slight decrease in the onset temperature of decomposition for the PLA/PEC sample. However, the quantity of remaining char residue was significantly increased in this sample. Moreover, a significant reduction in the pHRR (42\%) and THR (20\%) was observed by PCFC analysis compared with the neat PLA printed sample. This study showed that it is possible to print a new flame-retardant material.

Several reports have been written by Koo's research team [187-189] on the flame retardancy of PA6, polyamide 11 (PA11), and polyamide 12 (PA12) for AM processes. This research team especially works on AM for ablative and thermal protection systems (TPS) for aerospace and military applications. TPSs have been used in some parts of spacecraft, missile launching or rocket motors, which must be protected from high-temperature thermal sources. Koo et al. [189] developed the PA6 nanocomposite flame retardant compatible with the FDM to be used in ablative thermal protection systems. The flame-retardant PA6 contained 15 wt.\% Exolit ${ }^{\circledR} \mathrm{OP} 1312$ (organic aluminum phosphinate), $5 \mathrm{wt.} \%$ Cloisite 30B, and $5 \mathrm{wt} . \%$ of a maleated triblock copolymer containing

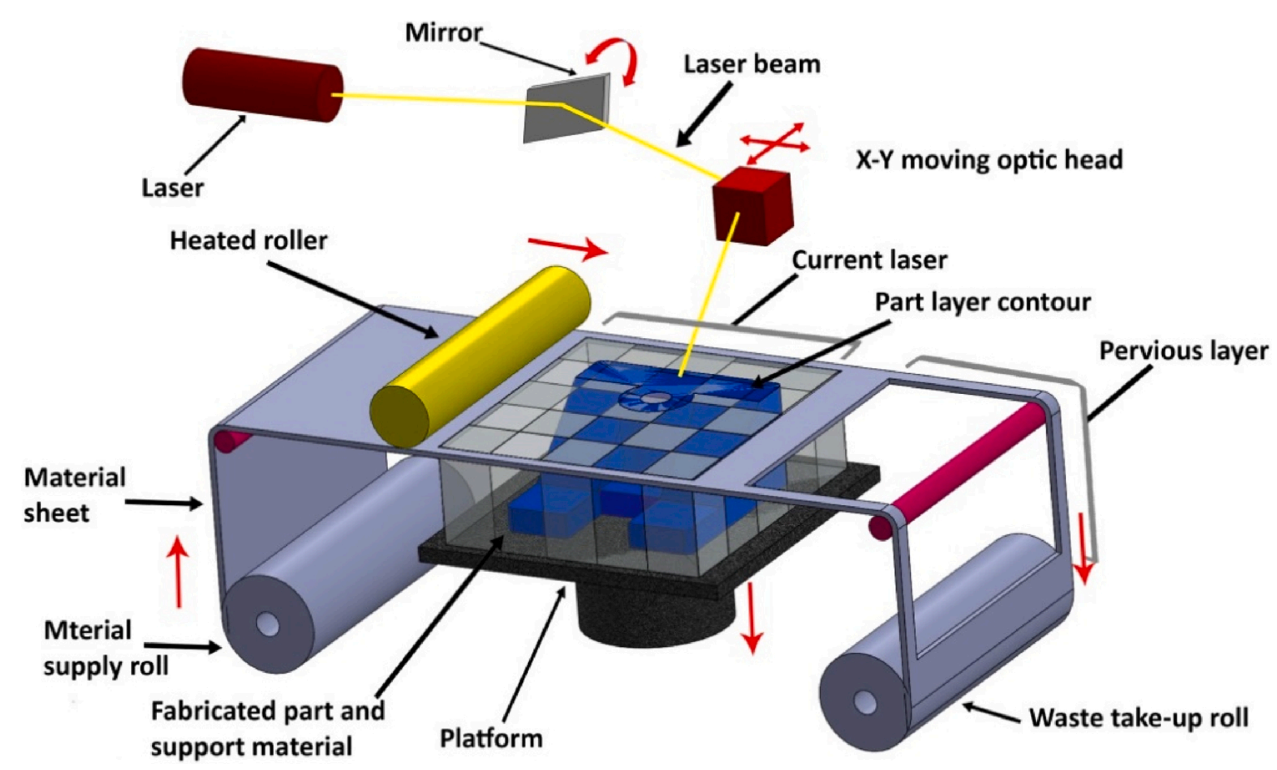

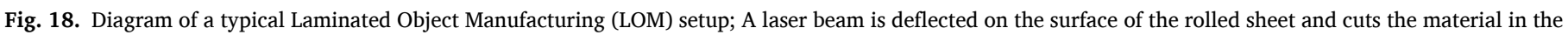
shape of the designed object, then the feeding system adds layers one by one on top of each other to build the final products [169]. 
Table 4

AM strategies proposed for the polymers along with their benefits and drawbacks [122].

\begin{tabular}{|c|c|c|c|c|}
\hline $\begin{array}{l}\text { Categorized } \\
\text { Techniques }\end{array}$ & $\begin{array}{l}\text { Typical } \\
\text { Resolution }\end{array}$ & $\begin{array}{l}\text { Typical } \\
\text { Materials }\end{array}$ & Advantages & Disadvantages \\
\hline \multicolumn{5}{|l|}{ Vat Photopolymerization } \\
\hline Exposure from top & $50-100 \mu \mathrm{m}$ & Acrylates/epoxides & $\begin{array}{l}\text { Excellent surface quality and } \\
\text { precision }\end{array}$ & Limited mechanical properties \\
\hline $\begin{array}{l}\text { Continuous Liquid Interface Production } \\
\text { (CLIP) }\end{array}$ & $75 \mu \mathrm{m}$ & Acrylates & High build speed & Low-viscosity resins required \\
\hline Exposure from bottom & $25-100 \mu \mathrm{m}$ & Acrylates/epoxides & $\begin{array}{l}\text { Low initial vat volume; better } \\
\text { surface quality }\end{array}$ & Limited mechanical properties \\
\hline Multiphoton lithography & $0.1-5 \mu \mathrm{m}$ & Acrylates & Very high resolution & Low build speed; limited materials \\
\hline \multicolumn{5}{|l|}{ Powder Bed Fusion } \\
\hline SLS & $50-100 \mu \mathrm{m}$ & PA12, PEEK & $\begin{array}{l}\text { Better mechanical properties; } \\
\text { less anisotropy }\end{array}$ & $\begin{array}{l}\text { Rough surfaces; poor reusability of } \\
\text { unsintered powder }\end{array}$ \\
\hline \multicolumn{5}{|l|}{ Material and Binder Jetting } \\
\hline Polyjet & $25 \mu \mathrm{m}$ & Acrylates & $\begin{array}{l}\text { Fast; allows } \\
\text { multimaterial AM }\end{array}$ & Low viscosity ink required \\
\hline Aerosol jet printing & $10 \mu \mathrm{m}$ & Conductive inks/dielectrics & $\begin{array}{l}\text { high resolution; low temp } \\
\text { process }\end{array}$ & Low viscosity ink required \\
\hline 3D printing (binder jetting) & $100 \mu \mathrm{m}$ & Starch, PLA, ceramics & $\begin{array}{l}\text { Fast; allows multimaterial AM; } \\
\text { low temp }\end{array}$ & $\begin{array}{l}\text { Limited strength of parts; rough } \\
\text { surfaces }\end{array}$ \\
\hline \multicolumn{5}{|l|}{ Sheet Lamination } \\
\hline Laminated Object Manufacturing (LOM) & $200-300 \mu \mathrm{m}$ & PVC, paper & Compact desktop 3D printer & $\begin{array}{l}\text { Limited materials; low resolution; } \\
\text { high anisotropy }\end{array}$ \\
\hline \multicolumn{5}{|l|}{ Material Extrusion } \\
\hline $\begin{array}{l}\text { Fused deposition modeling (FDM), Fused } \\
\text { filament fabrication (FFF) }\end{array}$ & $100-150 \mu \mathrm{m}$ & ABS, PLA, PC, HIPS & $\begin{array}{l}\text { Inexpensive machines and } \\
\text { materials }\end{array}$ & $\begin{array}{l}\text { Rough surfaces; high temperature } \\
\text { process }\end{array}$ \\
\hline 3D dispensing & $100 \mu \mathrm{m}$ to $1 \mathrm{~cm}$ & $\begin{array}{l}\text { thermo-plastics, composites, } \\
\text { photoresins, hydrogels, biomaterials }\end{array}$ & broad range of materials & $\begin{array}{l}\text { rough surfaces; narrow viscosity } \\
\text { process window }\end{array}$ \\
\hline
\end{tabular}

styrene-hydrogenated butadiene-styrene (SEBS-g-MA). The FR filaments were prepared using a twin-screw extruder and appropriate samples FDM printed for UL-94 measurements, in which they rated V-0. Moreover, Oxy-acetylene Test Bed (OTB) was performed according to ASTM E285, and the results confirmed that the FR-PA6 sample met the requirements for being used in TPS materials. Koo and his coworkers also reported the preparation of flame-retardant PA11 and PA12 for manufacturing via selective laser sintering [188]. Several nanoparticles have been examined by incorporating them into a bio-based PA11 (Rilsan ${ }^{\circledR}$ ) and PA12 including MMT, carbon nanofibers, and nanosilica to enhance its thermal stability, flame retardancy, and mechanical properties. The blend was prepared in a twin-screw extruder and then injection molded to obtain the samples for fire tests, where enhanced flame retardancy could be ascribed to the use of the above-mentioned nanoparticles. They also succeeded in preparing SLS powder from some of the formulations and in printing some complex shapes. However, the SLS printed samples were not tested for retardancy. Koo's research team also worked on the 3D printing of high performance polymers such as poly(ether ketone ketone) (PEKK) [190,191], polyether ether ketone (PEEK), and polyetherimide (PEI) [192,193], Fig. 19 (b). Since these polymers are highly resistant against fire, no flame retardant was added to them. First, they used an extruder to produce the printable filaments with a diameter of $1.75 \mathrm{~mm}$. Then, they fabricated the polymeric samples via the FFF printer with a nozzle diameter of $0.6 \mathrm{~mm}$. Based on the polymer type, they applied various printing parameters including infill density, raster angle, printing temperature, and speed.

The second strategy consists in printing core-skin structures. This type of dual structure was inspired by some existing technologies such as co-injection molding, and coating. Regazzi et al. [194,195] investigated a core-skin structure in which control of the skin thickness was more feasible compared to existing technologies, Fig. 19(a).2. Several formulations containing PLA, APP, melamine cyanurate, montmorillonite, and sepiolite were prepared through fused filament fabrication. The core of the sample was made of neat PLA and the 1-mm-thick skin of the flame-retardant PLA. Similar formulations were prepared by injection molding, without the core-skin structure, and some were printed with FR PLA. The results obtained in cone calorimetry tests showed that the

Table 5

Commercially available FR polymers for potent to 3D printing.

\begin{tabular}{|c|c|c|c|c|c|}
\hline Product name & Company & Type of polymer & UL-94 rate & Method for printing & Reference \\
\hline Onyx FR & Markforged & PA6 & $\mathrm{V}-0$ & FFF & [170] \\
\hline PA6/66-GF20 FR LS Using Exolit ${ }^{\circledR}$ & Clariant & PA6/66 & $\mathrm{V}-0, \mathrm{~V}-2$ & FFF & [171] \\
\hline Firewire ${ }^{\circledR}$ FR-ABS & Firewire & ABS & $\mathrm{V}-0$ & FFF & [172] \\
\hline ABSpro Flame Retardant & Formfutura & ABS & $\mathrm{V}-0$ & FFF & [173] \\
\hline Flame Retardant PLA & ECO & PLA & $\mathrm{V}-0$ & FFF & [174] \\
\hline Flame retardant $\mathrm{ABS}$ & Atomic Filament & ABS & $\mathrm{V}-0$ & FFF & [175] \\
\hline Evolution FR & Cubicure & Halogen-free photopolymer & $\mathrm{V}-0$ & SLA & [176] \\
\hline PA 2210 FR & Materialise & $\mathrm{PA}$ & $\mathrm{V}-0$ & SLS & [177] \\
\hline PA2241 FR & EOS GmbH & PA12 & & SLS & [178] \\
\hline ULTEM 9085 & Materialise & Amorphous thermoplastic polyetherimide & $\mathrm{V}-0$ & FDM & [177] \\
\hline Windform FR1, FR2 & CRP Technology & $\mathrm{PA}$ & $\mathrm{V}-0$ & SLS & [179] \\
\hline 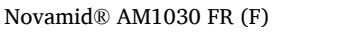 & DSM & PA6/66 & $\mathrm{V}-0, \mathrm{~V}-2$ & FDM & [180] \\
\hline PA-AF (Previously called Alumide) & Materialise & Blend of PA and aluminum powders & - & FDM & [181] \\
\hline Nylon 11 FR* & Stratasys & $\mathrm{PA}$ & & SLS & [182] \\
\hline Nylon 12 FR* & Stratasys & PA & & SLS & [182] \\
\hline Essentium PEEK & Essentium Materials & PEEK & $\mathrm{V}-0$ & FDM & [183] \\
\hline
\end{tabular}

* Containing halogenated FR. 


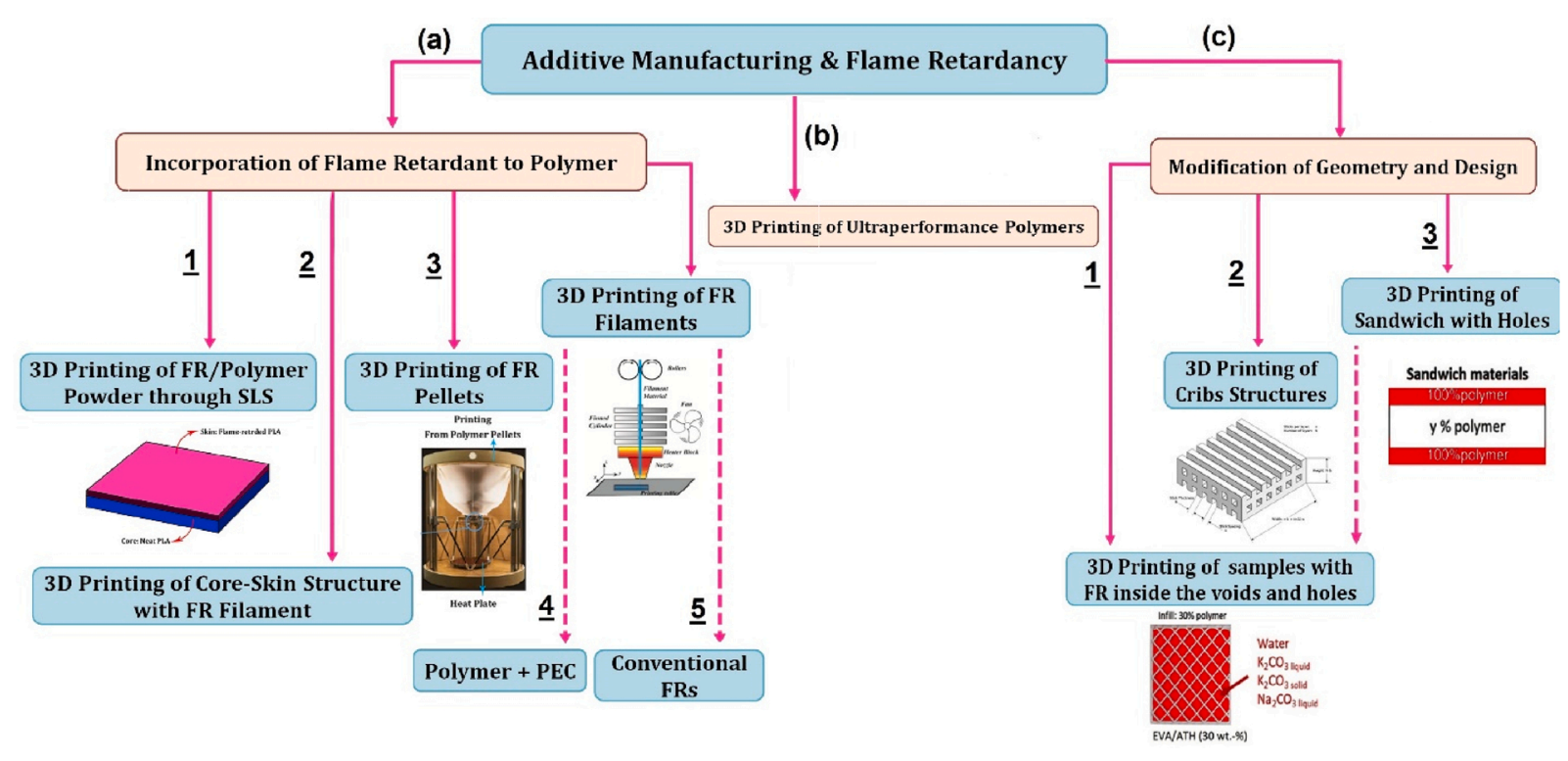

Fig. 19. A classification proposed by the authors of the present review of different strategies used to improve the flame retardancy of polymers in AM, according to the survey of the literature.

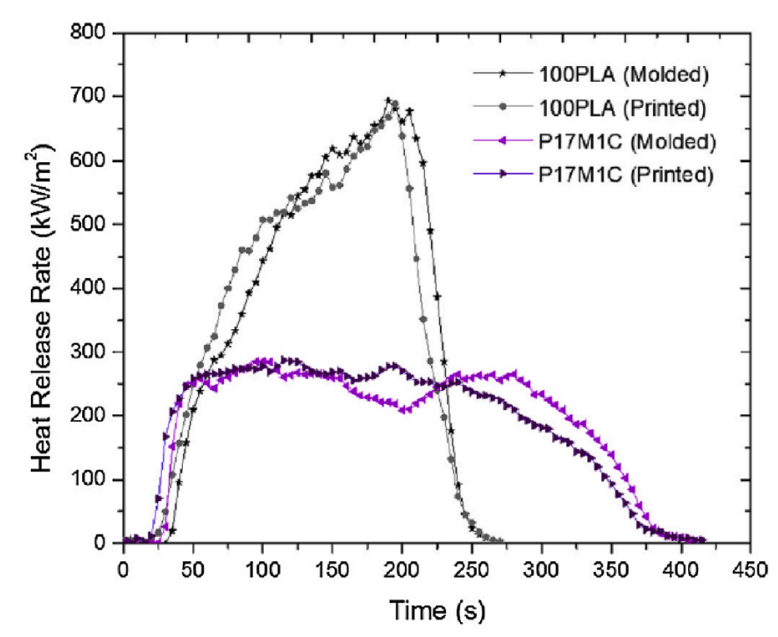

Fig. 20. HRR curves of the molded and printed samples obtained from cone calorimetry tests (100PLA: neat PLA, P17M1C: sample containing PLA together with $17 \mathrm{wt} . \%$ melamine polyphosphate and $1 \mathrm{wt} \%$ Cloisite 30B [184].

fire behaviors of the injected and printed samples were similar, except the TTI which was shorter for the printed samples due to their porous structure. Moreover, it was demonstrated that when the FR was concentrated at the surface of the printed sample, in the skin layer, and close to the radiated surface, improved fire retardancy was obtained for some formulations, compared with the printed sample containing FR within the whole sample. According to the authors, this was a promising result suggesting that the mechanical properties could be guaranteed and also the fire behavior modulated by adjusting the skin thickness as well as the FR concentration.

The third strategy is to modify the geometry and design in the printing of materials in order to modulate their flammability behavior, Fig. 19(c). This concept was introduced for the first time by Kraft et al. [196]. Their work was essentially based on Block's model [197] for wooden cribs. Block defined a porosity factor to distinguish between the porosity-controlled regime and the surface area regime. In the crib structure presented by Block, some parameters were defined such as the square prisms with a defined thickness, spacing between them, the number of prisms per layer, and the number of layers, Figs. 19(c) and 22 a. In this model, the spacing between the prisms and the number of layers of prisms controls the burning rate in the porosity-controlled regime. However, these parameters have no effect on the surface area-controlled regime. Kraft et al. [196] applied the Block's porosity model to the samples manufactured by 3D printing. They prepared the ABS cribs using a Stratasys Fortus $400 \mathrm{mc}$ system printer and also by the injection molding method, Fig. 22a-c. The samples were analyzed using cone calorimeter tests. They innovatively presented the pHRR obtained in cone calorimeter tests as a function of the porosity factor, Fig. 23. The cribs with higher porosity factors collapsed in a shorter time and resulted in higher pHRR, while the pHRR was reduced in the samples with porosity factors less than one. The authors concluded that the two burning regimes in function of the porosity factor should be considered in designing structures for fire safety, whatever the materials. However, the difference between the printed and molded samples was not elucidated, since the samples collapsed after $60 \mathrm{~s}$ of flaming.

The last strategy consists of the 3D fabrication of walled/hole/pore structures filled with water or FRs, Fig. 19(C).1-(C).3. This concept has already been used in steel structures $[198,199]$ and fabric laminates [200]. Brooks et al. [201] introduced the concept for the first time in the $3 \mathrm{D}$ printing of polymers having the possibility of printing internal lattices. A methacrylic photoactive resin (GPCL02) was used to prepare rectangular samples by the SLA printing method, Fig. 24d. Cone calorimetry tests showed that the TTI significantly increased from $32 \mathrm{~s}$ for the unfilled sample to $283 \mathrm{~s}$ (almost nine times) for the water-filled

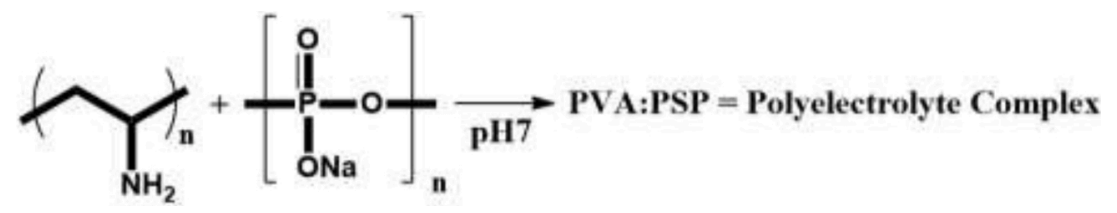

Fig. 21. Polyelectrolyte complex (PEC) of polyvinylamine (PVA) and sodium polyphosphate (PSP), used by Kolibaba et al. [186]. 


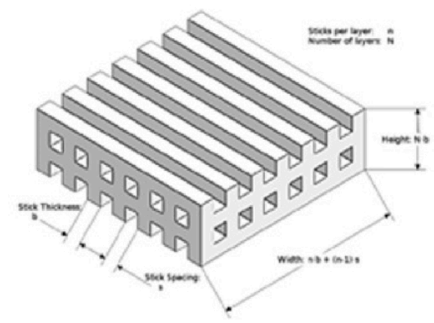

a

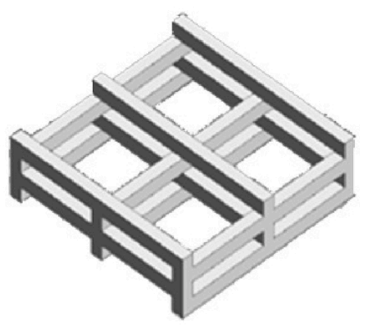

b

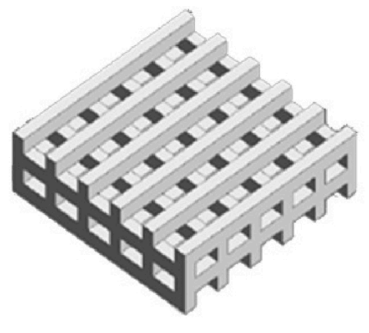

c

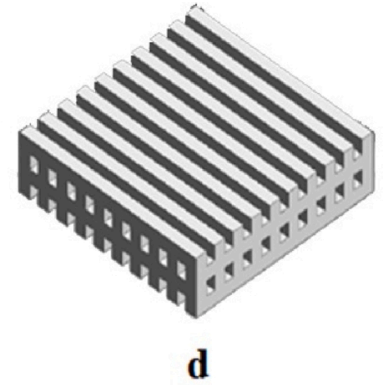

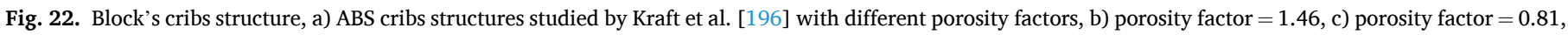
d) porosity factor $=0.33$ [196].

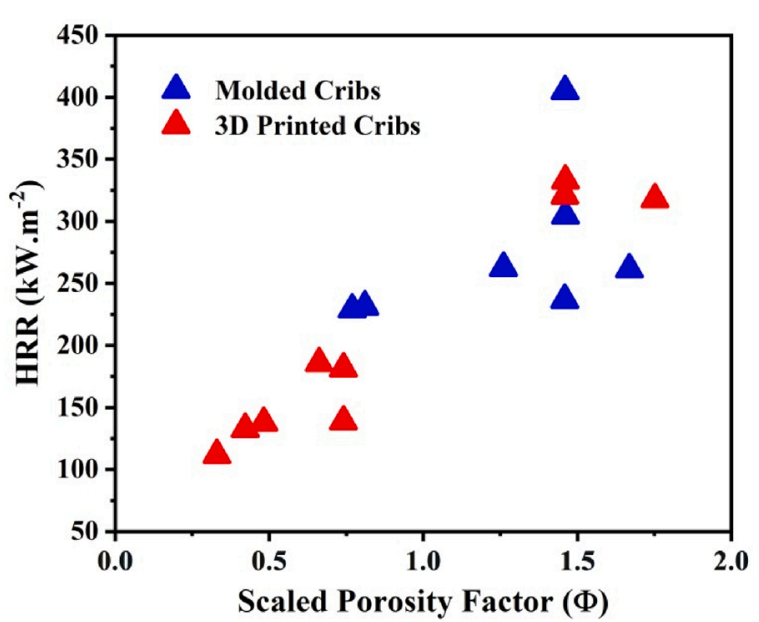

Fig. 23. Peak heat release rate (pHRR) as a function of porosity factors [196].

sample. However, the pHRR did not change significantly. The authors also demonstrated that it was possible to print some other water-filled parts with complex shapes and better flame behavior.

Geoffroy et al. [202] investigated the flame retardancy of sandwich type $3 \mathrm{D}$ printed materials in which the core part had different infill densities, $30 \%$ and $50 \%$. The skins were printed exclusively with FR EVA, Fig. 25. They also prepared the sandwich samples with a core of 30 $\%$ infill and several materials (water, potassium carbonate $\left(\mathrm{K}_{2} \mathrm{CO}_{3}\right)$ in solution and solid state, and sodium carbonate $\left(\mathrm{Na}_{2} \mathrm{CO}_{3}\right)$ in solution) inside the pores. ATH and EG were blended in a twin-screw extruder and then the pellets obtained were used to print the samples in an FDM printer (Pollen 3D printer). Overall, fourteen formulations were prepared and two of the strategies mentioned above, modification of design and holes/pores filled with FR, were examined in their work.

First, their results showed that the presence of holes containing $50 \%$ and $70 \%$ air led to better flame-retardant properties compared with the filled samples. The improvement in the fire behavior of materials with voids can be explained based on different variables such as using lowflammability material, lower thermal conductivity, and reduction in the heat propagation rate due to the presence of voids in the core of materials. Then, the air was replaced by water, $\mathrm{K}_{2} \mathrm{CO}_{3}$, or $\mathrm{Na}_{2} \mathrm{CO}_{3}$ in solid and dissolved states. The fire behavior of samples was not improved in the presence of water due to the low quantity of water inside the voids. No positive effect was detected, in the presence of $\mathrm{K}_{2} \mathrm{CO}_{3}$ in powder form either, due to its high decarbonization temperature $\left(891^{\circ} \mathrm{C}\right.$ ). However, when $\mathrm{K}_{2} \mathrm{CO}_{3}$ or $\mathrm{Na}_{2} \mathrm{CO}_{3}$ were used in dissolved form, the flame behavior was significantly improved, as demonstrated by a significant fall in pHRR in cone calorimetry tests, Fig. 26. The release of potassium $(\mathrm{K}) / \mathrm{H}_{2} \mathrm{O}, \mathrm{KOH}, \mathrm{CO}_{2}$, and $\mathrm{H}_{2} \mathrm{O}$ into the gas phase led to the dilution of gas phase and free radical reactions.

Table 6 summarizes the information extracted from the publications discussed above. Overall, there are three main strategies for enhancing the flame retardancy of 3D printed samples, Fig. 19.

Recently, the 3D printing of a shape memory PET with selfhealability and flame-retardant properties was reported by Chen et al. [203]. They prepared a new material through the copolymerization of PET and a new monomer containing phenylimide and phenylacetylene, named PEPN, Fig. 27. The prepared copolymer was printed using an FDM 3D printer. In this copolymer, the П-П stacking between phenylacetylene groups provides the material with self-healing and shape memory properties due to the reversibility of these interactions. The flammability test showed a significant improvement in the flame behavior of this copolymer compared with neat PET. The LOI value increased greatly to 34.5 , compared with 21.8 for neat PET. The new copolymer was rated V-0 in UL-94 tests, while PET is unrated. In PCFC tests, the pHRR (-50.5\%) and THR (-32.5\%) values also decreased significantly compared with neat PET. The authors explained the improvement in the copolymer's flame behavior as being due to the crosslinking between copolymer chains during combustion and the increase in melt viscosity, together with the crosslink with the unsaturated $\mathrm{C}=-\mathrm{N}$ group generated from the phenylimide during combustion.

\section{Q Polymer $\square$ Water}

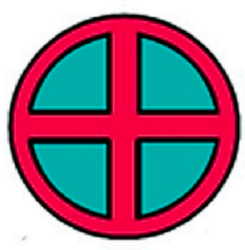

a)

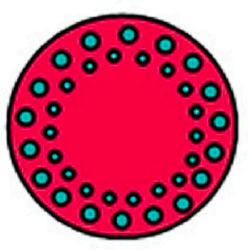

b)

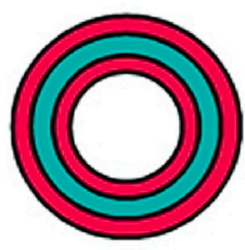

c)

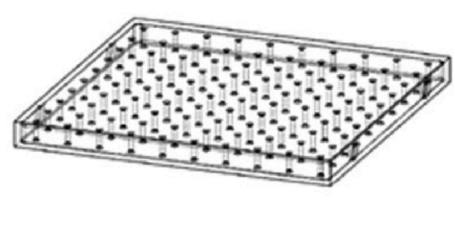

d)

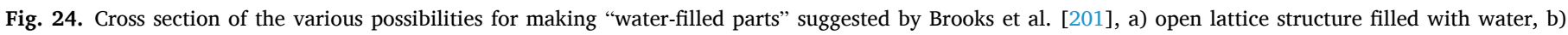

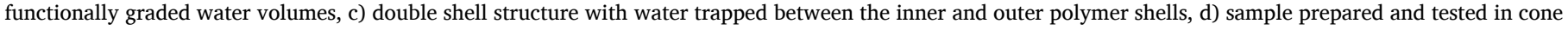
calorimeter by Brooks et al. [201]. 


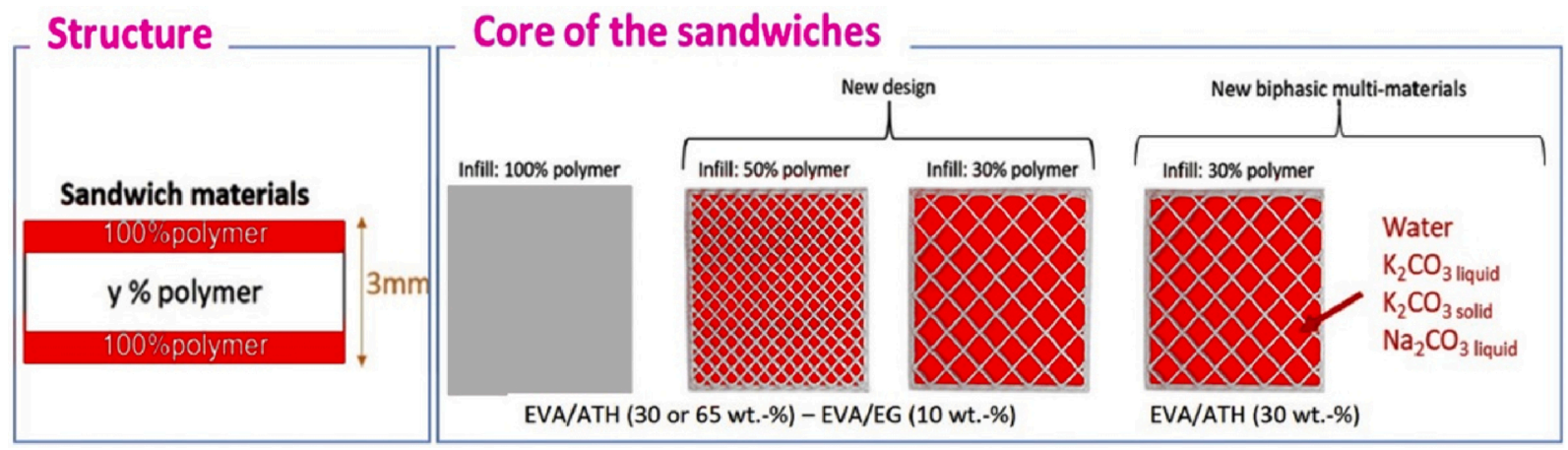

Fig. 25. Sandwich structures containing voids/pores prepared by Geoffroy et al. [202].

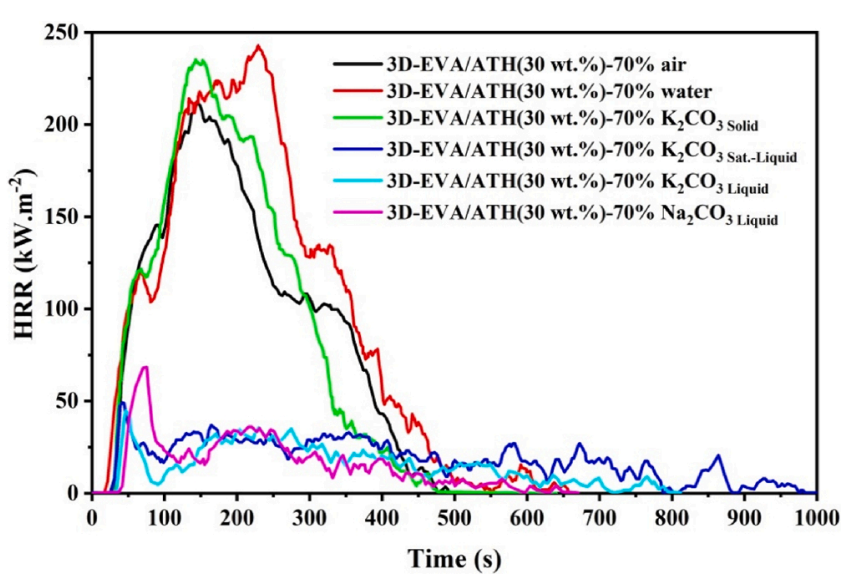

Fig. 26. HRR curves demonstrating the fire behavior of biphasic multimaterials prepared by Geoffroy et al. [202].
Consequently, dripping decreased and the formation of a carbonaceous shield on the surface was promoted, and this condensed phase mechanism was responsible for the improvement in flame retardancy.

\section{Concluding remarks and future perspectives}

The flammability of polymers is a real problem. FRs play a key-role in the safety of our lives. Therefore, the science of flame retardancy and development of flame-retardant polymer materials is in constant evolution and still has challenges to face in the future due to fire and environmental regulations, and the massive use of polymers in almost all sectors of our lives. New fire regulations are currently under preparation for some sectors such as automobiles and buildings. In the meantime, new manufacturing technologies are also constantly advancing and therefore flame-retardant solutions need to be adaptable to them. The present review summarizes recent progress in the flame retardancy of polymers and attempts to visualize the worth of using 3D printing technology for developing next generation of flame retardants.

This review places emphasis on the fact that 3D printing provides new dimensions for the flame retardancy of polymeric materials by

Table 6

Some important information extracted from the literature on AM of flame retardant polymers systems.

\begin{tabular}{|c|c|c|c|c|c|}
\hline Polymer & Flame retardant & Wt.\% FR & Printing Method & Specifications & Ref. \\
\hline EVA & $\begin{array}{l}\text { Aluminum tri-hydroxide (ATH), expandable } \\
\text { graphite, air, water, potassium carbonate } \\
\text { solubilized or in powder form sodium carbonate } \\
\text { inside }\end{array}$ & $\begin{array}{l}30,65(\mathrm{ATH}) \\
10 \text { (EG) }\end{array}$ & $\begin{array}{l}\text { FDM using } \\
\text { Pellets polymer }\end{array}$ & $\begin{array}{l}\text { Printing temperature } 130^{\circ} \mathrm{C} \text {, Printing speed } \\
20 \mathrm{~mm} / \mathrm{s} \text {, Nozzle diameter } 0.8-1 \mathrm{~mm}\end{array}$ & [202] \\
\hline PA6 & $\begin{array}{l}\text { Organically modified Montmorillonite (MMT) \& } \\
\text { Exolit }{ }^{\circledR O P} 1312\end{array}$ & $\begin{array}{l}5 \text { (MMT) } \\
15 \text { (Exolit) }\end{array}$ & FFF & $\begin{array}{l}\text { Nozzle temperature } 240^{\circ} \mathrm{C} \text {, Printing speed } \\
30-50 \mathrm{~mm} / \mathrm{min}\end{array}$ & [189] \\
\hline PLA & $\begin{array}{l}\text { Melamine polyphosphate (MPP) and Cloisite 30B } \\
\text { (C-30B) }\end{array}$ & $\begin{array}{l}17 \text { (MPP) } \\
1 \text { (C-30B) }\end{array}$ & FDM & Printing temperature $229^{\circ} \mathrm{C}$, flow rate $90 \mathrm{~mm} / \mathrm{s}$ & [184] \\
\hline PLA & Polyvinylamine and poly(sodium phosphate) & 25 & FFF & Printing rate $3000 \mathrm{~mm} / \mathrm{min}$ & [186] \\
\hline EVA & ATH, expandable graphite (EG) & $\begin{array}{l}30 \text { and } 65 \\
\text { (ATH)- } \\
10 \text { (EG) }\end{array}$ & $\begin{array}{l}\text { FDM using } \\
\text { Pellets polymer }\end{array}$ & $\begin{array}{l}\text { Printing temperature } 130^{\circ} \mathrm{C} \text {, Printing speed } \\
20-30 \mathrm{~mm} / \mathrm{s} \text {, Nozzle diameter } 0.4-1 \mathrm{~mm}\end{array}$ & [185] \\
\hline $\begin{array}{l}\text { Methacrylic photoactive } \\
\text { resin (GPCL02) }\end{array}$ & Water & - & SLA & $\begin{array}{l}\text { Layer } \\
\text { heights } 0.1 \mathrm{~mm}\end{array}$ & [201] \\
\hline PLA & $\begin{array}{l}\text { Ammonium polyphosphate, Melamine } \\
\text { cyanurate, MMT, Sepiolite }\end{array}$ & 0.75 to 18 & FFF & $\begin{array}{l}\text { Filament diameter } 2.85 \mathrm{~mm} \text {, Nozzle diameter } \\
0.4 \mathrm{~mm}\end{array}$ & $\begin{array}{l}{[194,} \\
195]\end{array}$ \\
\hline ABS & - & - & FDM & - & [196] \\
\hline
\end{tabular}
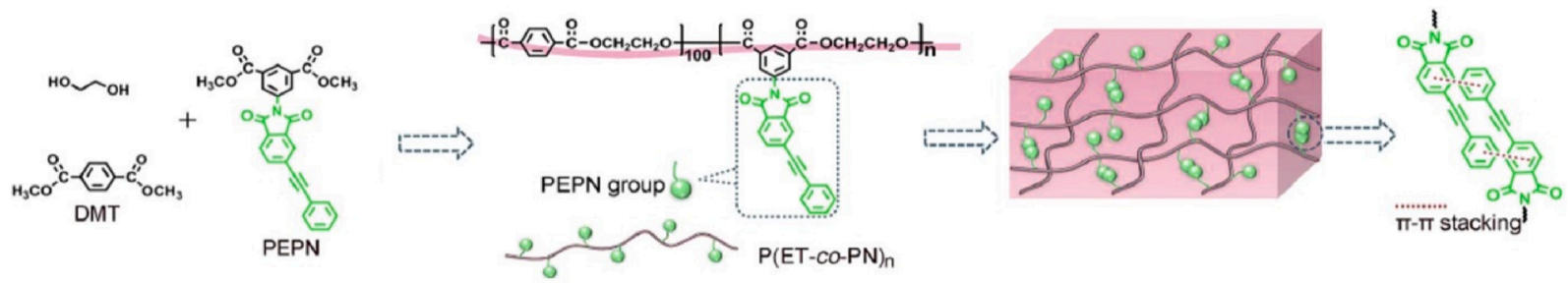

Fig. 27. Preparation of the new copolymer by Chen et al. [203], and reversible П-П stacking networks between phenylacetylene groups. 
modulating the density or creating pores insides the printed materials, thus improving thermal conductivity and diffusivity inside the material. Furthermore, 3D printing technology gives the possibility to produce different layers on the surface or inside the material. These layers can incorporate different types of flame-retardant additives and; thus; flame retardancy can be modulated from the bottom (adjacent to the substrate) to the top layer (exposed to the fire front). The most promising feature of this approach is that an inherently flame retardant compound of polymer and flame retardant additive will be shaped in 3D printing process, while the performance of the counterpart produced by conventional processes such as extrusion and injection molding depends on the state of dispersion of flame retardant within the polymer matrix as well as processing conditions. Furthermore, the use of 3D printing has the benefits of enabling the design of complex geometries.

In the present review, the current status of research on the flame retardancy of some 3D printed thermoplastics was reviewed. It is worth mentioning that the number of comprehensive studies on this subject is still limited. Moreover, there is no report on the flame retardancy of 3D printed thermoset materials or fiber-reinforced composites. Since these materials are in constant development in 3D printing technology, their flame retardancy needs to be considered. Furthermore, although size limitation is currently challenging in 3D printing technology, it is probable that fire risk scenarios may vary in function of the scale at which materials are used.

Given that the use of 3D printed materials will become widespread in the near future, it is necessary to define new regulations, standards, instructions/legislation, and testing methods for flame-retardant 3D printed materials. Concerning the fire behavior of polymer materials processed by 3D printing, the Blue Card program prepared by the UL safety organization aims to provide accurate information on the fire performance of materials (in UL-94, Hot Wire Ignition and High Arc Ignition tests) and their printing conditions. For example, it includes information on the fire performance achieved in these 3 tests and the 3D building process conditions (material extrusion, powder bed fusion systems, vat polymerization...). In addition to the 3D printer model used, it includes the most important printing parameters, such as raster angle, air gap, print speed, post processing for material extrusion, and Hatch spacing, scan strategy, scan speed and laser power for powder bed fusion systems.

In the near future, one of the most important challenges for the AM sector will be the possibility to have more options in terms of polymer types with appropriate properties including flame retardancy. Therefore, the adaptation of flame retardants to polymers newly used in 3D printing technologies should be considered as an important subject of research. PLA, as a bio-based polymer, is currently one of the most used polymers in 3D printing technology. However, the flame-retardant solutions suggested by several authors for PLA and reviewed in the present paper were non-bio-based. In the future, appropriate bio-based flame retardants should be prepared for PLA and other, non-bio-based polymers. Generally, development of bio-based FRs is a direct response to raised awareness related to health and environmental issues. Nevertheless, some bio-based solutions are still at the research stage and not applicable even to the blending process in industry. Moreover, the production cost versus efficiency of some biobased FRs is still being debated, and needs to be affordable for industry.

3D printing by SLS appears to be a simple way of developing a flameretardant plastic by printing a simple physical blend of both polymer and flame-retardant powders. However, the practice has shown that the process is more complex for several reasons, among which we can cite, (i) the need to use powders presenting similar granulometry and shape to ensure good homogenization and flow of powders when filling the printing bed from the reservoir bed, for example, (ii) the thermal stability of the flame retardant powders during the process. Indeed, the simple mixing of polymer powders with organophosphorus FRs, for example, could induce flame retardant decomposition and the generation of volatiles. This is the case, for example, when printing flame retardant polyamides by dry blending the polymer powder and existing Exolite ${ }^{\circledR}$ additives directly. This process has been shown to be difficult because of problems due to sublimation and deposition of volatiles on the laser lens [204]. The development of powders by milling flame-retardant polymers is a proposed way to address this limitation. However, we can also expect researchers to propose other solutions such as grafting organophosphorus molecules directly on the surface of polymer particles.

\section{Declaration of Competing Interest}

The authors declare that they have no known competing financial interests or personal relationships that could have appeared to influence the work reported in this paper.

\section{References}

[1] D. Irvine, J. McCluskey, I. Robinson, Polym. Degrad. Stab. 67 (2000) 383-396. [2] J. Xin, C. Huang, Fire Saf. J. 62 (2013) 72-78.

[3] S.T. McKenna, N. Jones, G. Peck, K. Dickens, W. Pawelec, S. Oradei, S. Harris, A. A. Stec, T.R. Hull, J. Hazard. Mater. 368 (2019) 115-123.

[4] A.B. Morgan, J.W. Gilman, Fire Mater. 37 (2013) 259-279.

[5] M. Lewin, Polym. Degrad. Stab. 88 (2005) 13-19.

[6] B. Schartel, C.A. Wilkie, G. Camino, J. Fire Sci. 35 (2017) 3-20.

[7] A.B. Morgan, Polym. Rev. 59 (2019) 25-54.

[8] F. Laoutid, L. Bonnaud, M. Alexandre, J.M. Lopez-Cuesta, P. Dubois, Mater. Sci. Eng. R Rep. 63 (2009) 100-125.

[9] S. Shaw, Rev. Environ. Health 25 (2010) 261-306.

[10] P. Xiong, X. Yan, Q. Zhu, G. Qu, J. Shi, C. Liao, G. Jiang, Environ. Sci. Technol. 53 (2019) 13551-13569.

[11] A.R. Horrocks, Polym. Degrad. Stab. 96 (2011) 377-392.

[12] K.A. Salmeia, S. Gaan, G. Malucelli, Polymers 8 (2016) 319.

[13] J.W. Mitchell, Non-Halogenated Flame Retardant Handbook (2014) 1-16.

[14] Y. Hu, X. Wang, Flame Retardant Polymeric Materials: A Handbook, CRC Press, 2019.

[15] A. Perujo, G. Van Grootveld, H. Scholz, New Generation of Electric Vehicles, 2012, pp. 3-28.

[16] S.A.M. Tofail, E.P. Koumoulos, A. Bandyopadhyay, S. Bose, L. O’Donoghue, C. Charitidis, Mater. Today 21 (2018) 22-37.

[17] A. Bandyopadhyay, B. Heer, Mater. Sci. Eng. R Rep. 129 (2018) 1-16.

[18] N. Shahrubudin, T.C. Lee, R. Ramlan, Procedia Manuf. 35 (2019) 1286-1296.

[19] J.A. Brown, Modern Manufacturing Processes, Industrial Press Inc., 1991.

[20] D. Hotza, C.M. Gomes, J. Günster, Advances in Additive Manufacturing Processes and Materials, SAGE Publications Sage UK, London, England, 2014.

[21] J.-J. Wu, L.-M. Huang, Q. Zhao, T. Xie, Chin. J. Polym. Sci. 36 (2018) 563-575.

[22] X. Kuang, D.J. Roach, J. Wu, C.M. Hamel, Z. Ding, T. Wang, M.L. Dunn, H.J. Qi, Adv. Funct. Mater. 29 (2019) 1805290.

[23] A.D. Valino, J.R.C. Dizon, A.H. Espera, Q. Chen, J. Messman, R.C. Advincula, Prog. Polym. Sci. 98 (2019) 101162.

[24] X. Wang, M. Jiang, Z. Zhou, J. Gou, D. Hui, Compos. Part B Eng. 110 (2017) $442-458$.

[25] A.M. Henderson, IEEE Electr. Insul. Mag. 9 (1993) 30-38.

[26] F.-L. Jin, X. Li, S.-J. Park, J. Ind. Eng. Chem. 29 (2015) 1-11.

[27] M. Biron, Thermosets and Composites: Material Selection, Applications, Manufacturing and Cost Analysis, Elsevier, 2013.

[28] F. Wang, Q. Wang, X. Wang, For. Prod. J. 60 (2010) 668-678.

[29] R.R. Hindersinn, Historical Aspects of Polymer Fire Retardance, ACS Publications, 1990.

[30] L. Van Wabeeke, Int. Polym. Sci. Technol. 29 (2002) 1-5.

[31] R. Baldwin, P. Thomas, Fire Saf. Sci. 963 (1973) -1-1.

[32] J. Zhang, X. Mi, S. Chen, Z. Xu, D. Zhang, M. Miao, J. Wang, Chem. Eng. J. 381 (2020) 122719.

[33] E.R. Rad, H. Vahabi, A.R. de Anda, M.R. Saeb, S. Thomas, Prog. Org. Coat. 135 (2019) 608-612.

[34] J. Sag, D. Goedderz, P. Kukla, L. Greiner, F. Schönberger, M. Döring, Molecules 24 (2019) 3746.

[35] H. Vahabi, M.R. Saeb, K. Formela, J.-M.L. Cuesta, Prog. Org. Coat. 119 (2018) $8-14$.

[36] V. Mittal, High Performance Polymers and Engineering Plastics, John Wiley \& Sons, 2011.

[37] A. Ramgobin, G. Fontaine, S. Bourbigot, Polym. Rev. 59 (2019) 55-123.

[38] The Flame Retardants Market, 2017. https://www.flameretardants-online.com /flame-retardants/market.

[39] S. Bocchini, G. Camino, Fire Retardancy of Polymeric Materials, 2, 2009.

[40] T. Hull, R. Law, A. Bergman, Environmental drivers for replacement of halogenated flame retardants. Polymer Green Flame Retardants, Elsevier, 2014, pp. 119-179.

[41] Plast. Addit. Compd. 3 (2001) 22-26.

[42] G. Abbasi, L. Li, K. Breivik, Environ. Sci. Technol. 53 (2019) 6330-6340.

[43] R. Lavandier, N. Quinete, R.A. Hauser-Davis, P.S. Dias, S. Taniguchi, R. Montone, I. Moreira, Chemosphere 90 (2013) 2435-2443. 
[44] e.V. Öko-Institut, ROHS Annex II Dossier for TBBP-A Restriction Proposal for Substances in Electrical and Electronic Equipment Under RoHS, 2019. https ://rohs.exemptions.oeko.info/fileadmin/user_upload/RoHS_Pack_15/4th_Consul tation/TBBPA_RoHS_Dossier_V2_final_20191204.pdf.

[45] H. Vahabi, R. Sonnier, L. Ferry, Polym. Int. 64 (2015) 313-328.

[46] C. Koch, M. Nachev, J. Klein, D. Köster, O.J. Schmitz, T.C. Schmidt, B. Sures, Environ. Sci. Technol. 53 (2019) 1453-1462.

[47] A. BSEF, Novel Brominated Polymeric Flame Retardant for Use in Polystyrene FOAMS, 2018. https://bsef.com/wp-content/uploads/2018/08/BSEF-Polymeri c-brochure-Digital.pdf.

[48] ICL Industrial Products, Flame Retardent Products, 2020. https://www.tri-iso. $\mathrm{com} /$ documents/ICL_Flame Retardants Brochure.pdf.

[49] I. Van der Veen, J. de Boer, Chemosphere 88 (2012) 1119-1153.

[50] S. Levchik, in: A.B. Morgan, C.A. Wilkie (Eds.), Non-Halogenated Flame Retardant Handbook, 2014, pp. 17-74.

[51] B. Schartel, Materials 3 (2010) 4710-4745.

[52] S.V. Levchik, E.D. Weil, J. Fire Sci. 24 (2006) 345-364.

[53] E.D. Weil, S.V. Levchik, M. Ravey, W. Zhu, Phosphorus, Sulfur, and Silicon and the Related Elements, 144, 1999, pp. 17-20.

[54] A. Granzow, J. Cannelongo, J. Appl. Polym. Sci. 20 (1976) 689-701.

[55] U. Braun, B. Schartel, Macromol. Mater. Eng. 293 (2008) 206-217.

[56] Q. Yao, S.V. Levchik, G.R. Alessio, Phosphorus-containing flame retardant for thermoplastic polymers, Google Patents, 2010.

[57] S.V. Levchik, Flame Retardant Polymer Nanocomposites, 2007, pp. 1-29.

[58] M. Klatt, in: A.B. Morgan, C.A. Wilkie (Eds.), Non-Halogenated Flame Retardant Handbook, 2014, pp. 143-168.

[59] C.-E. Wilén, R. Pfaendner, Design and utilization of nitrogen containing flame retardants based on $\mathrm{N}$-alkoxyamines, azoalkanes and related compounds. Polymer Green Flame Retardants, Elsevier, 2014, pp. 267-288.

[60] F.Y. Hshieh, Fire Mater. 22 (1998) 69-76.

[61] Pinfa Product Selector, Product Selector, 2018. https://www.pinfa.eu/product-se lector/.

[62] L. Costes, F. Laoutid, S. Brohez, P. Dubois, Mater. Sci. Eng. R Rep. 117 (2017) $1-25$.

[63] R. Sonnier, A. Taguet, L. Ferry, J.-M. Lopez-Cuesta, Towards Bio-based Flame Retardant Polymers, Springer, 2018.

[64] F. Carosio, A. Di Blasio, F. Cuttica, J. Alongi, G. Malucelli, Ind. Eng. Chem. Res. 53 (2014) 3917-3923.

[65] J. Alongi, R.A. Carletto, F. Bosco, F. Carosio, A. Di Blasio, F. Cuttica, V. Antonucci, M. Giordano, G. Malucelli, Polym. Degrad. Stab. 99 (2014) $111-117$.

[66] F. Bosco, R.A. Carletto, J. Alongi, L. Marmo, A. Di Blasio, G. Malucelli, Carbohydr. Polym. 94 (2013) 372-377.

[67] G. Laufer, C. Kirkland, A.B. Morgan, J.C. Grunlan, Biomacromolecules 13 (2012) 2843-2848.

[68] X. Wang, M.Q. Romero, X.-Q. Zhang, R. Wang, D.-Y. Wang, RSC Adv. 5 (2015) 10647-10655.

[69] X.-W. Chen, J.-P. Guan, G. Chen, X.-H. Yang, R.-C. Tang, Polymers 8 (2016) 122

[70] X.-W. Cheng, J.-P. Guan, R.-C. Tang, K.-Q. Liu, J. Clean. Prod. 124 (2016) $114-119$.

[71] L. Costes, F. Laoutid, L. Dumazert, J.-M. Lopez-cuesta, S. Brohez, C. Delvosalle, P. Dubois, Polym. Degrad. Stab. 119 (2015) 217-227.

[72] L. Costes, F. Laoutid, M. Aguedo, A. Richel, S. Brohez, C. Delvosalle, P. Dubois, Eur. Polym. J. 84 (2016) 652-667.

[73] L. Costes, F. Laoutid, S. Brohez, C. Delvosalle, P. Dubois, Eur. Polym. J. 94 (2017) 270-285.

[74] F. Laoutid, V. Karaseva, L. Costes, S. Brohez, R. Mincheva, P. Dubois, J. Renew. Mater. 6 (2018).

[75] F. Laoutid, H. Vahabi, M. Shabanian, F. Aryanasab, P. Zarrintaj, M.R. Saeb, Fire Mater. 42 (2018) 914-924.

[76] C. Réti, M. Casetta, S. Duquesne, S. Bourbigot, R. Delobel, Polym. Adv. Technol. 19 (2008) 628-635.

[77] R. Mincheva, H. Guemiza, C. Hidan, S. Moins, O. Coulembier, P. Dubois, F. Laoutid, Materials 13 (2020) 13.

[78] H. Vahabi, O. Eterradossi, L. Ferry, C. Longuet, R. Sonnier, J.-M. Lopez-Cuesta, Eur. Polym. J. 49 (2013) 319-327.

[79] H. Vahabi, H. Rastin, E. Movahedifar, K. Antoun, N. Brosse, M.R. Saeb, Polymers $12(2020) 1234$.

[80] P. Joseph, S. Tretsiakova-Mcnally, Polym. Adv. Technol. 22 (2011) 395-406.

[81] H. Vahabi, C. Longuet, L. Ferry, G. David, J.J. Robin, J.M. Lopez-Cuesta, Polym. Int. 61 (2012) 129-134.

[82] G. Beyer, C. Hopmann, Reactive Extrusion: Principles and Applications, John Wiley \& Sons, 2018.

[83] D.-Y. Wang, Y.-P. Song, L. Lin, X.-L. Wang, Y.-Z. Wang, Polymer 52 (2011) 233-238.

[84] P. Simonetti, R. Nazir, A. Gooneie, S. Lehner, M. Jovic, K.A. Salmeia, R. Hufenus, A. Rippl, J.-P. Kaiser, C. Hirsch, Compos. Part B Eng. 178 (2019) 107470.

[85] X. Qiu, Z. Li, X. Li, Z. Zhang, Chem. Eng. J. 334 (2018) 108-122.

[86] E.D. Weil, J. Fire Sci. 29 (2011) 259-296.

[87] B. ISO13943, British Standard Institution, London, 2010.

[88] J. Troitzsch, Plastics Flammability Handbook: Principles, Regulations, Testing, and Approval, Hanser, Munich, 2004.

[89] R. Sonnier, H. Vahabi, L. Ferry, J.-M. Lopez-Cuesta, Pyrolysis-Combustion Flow Calorimetry: A Powerful Tool to Evaluate the Flame Retardancy of Polymers, Fire and Polymers vi: New Advances in Flame Retardant Chemistry and Science, ACS Publications, 2012, pp. 361-390.
[90] V. Babrauskas, The cone calorimeter. SFPE Handbook of Fire Protection Engineering, Springer, 2016, pp. 952-980.

[91] B. Tawiah, B. Yu, R.K.K. Yuen, Y. Hu, R. Wei, J.H. Xin, B. Fei, Carbon 150 (2019) $8-20$.

[92] L. Ye, J. Ren, S.-y. Cai, Z.-g. Wang, J.-b. Li, Chin. J. Polym. Sci. 34 (2016) 785-796.

[93] Z.-Q. Liu, Z. Li, Y.-X. Yang, Y.-L. Zhang, X. Wen, N. Li, C. Fu, R.-K. Jian, L.-J. Li, D.-Y. Wang, Polymers 10 (2018) 1028.

[94] G. Huang, S. Chen, S. Tang, J. Gao, Mater. Chem. Phys. 135 (2012) 938-947.

[95] S. Qiu, Y. Zhou, X. Zhou, T. Zhang, C. Wang, R.K. Yuen, W. Hu, Y. Hu, Small 15 (2019) 1805175.

[96] A. Laachachi, N. Burger, K. Apaydin, R. Sonnier, M. Ferriol, Polym. Degrad. Stab. 117 (2015) 22-29.

[97] H. Vahabi, M. Jouyandeh, M. Cochez, R. Khalili, C. Vagner, M. Ferriol, E. Movahedifar, B. Ramezanzadeh, M. Rostami, Z. Ranjbar, B.S. Hadavand, M. R. Saeb, Prog. Org. Coat. 123 (2018) 160-167.

[98] M.M. Hirschler, Fire Mater. 41 (2017) 993-1006.

[99] B. Schartel, T.R. Hull, Fire Mater. Int. J. 31 (2007) 327-354.

[100] T. Hakkarainen, J. Fire Sci. 19 (2001) 284-305.

[101] B. Schartel, M. Bartholmai, U. Knoll, Polym. Degrad. Stab. 88 (2005) 540-547.

[102] H. Vahabi, B.K. Kandola, M.R. Saeb, Polymers 11 (2019) 407.

[103] E. Movahedifar, H. Vahabi, M.R. Saeb, S. Thomas, Molecules 24 (2019) 3964.

[104] M. Zhao, D. Yi, G. Camino, A. Frache, R. Yang, RSC Adv. 7 (2017) 861-869.

[105] W. He, H. Zhu, Y. Xiang, L. Long, S. Qin, J. Yu, Polym. Degrad. Stab. 144 (2017) $442-453$.

[106] T.M. Majka, A. Leszczyńska, B.K. Kandola, W. Pornwannachai, K. Pielichowski, Appl. Clay Sci. 139 (2017) 28-39.

[107] C. Kaynak, O. Polat, J. Fire Sci. 33 (2015) 87-112.

[108] J. Dahiya, B. Kandola, A. Sitpalan, A. Horrocks, Polym. Adv. Technol. 24 (2013) $398-406$.

[109] J.B. Dahiya, S. Rathi, H. Bockhorn, M. Haußmann, B.K. Kandola, Polym. Degrad. Stab. 97 (2012) 1458-1465.

[110] N. Hong, L. Song, T.R. Hull, A.A. Stec, B. Wang, Y. Pan, Y. Hu, Mater. Chem. Phys. 142 (2013) 531-538.

[111] B. Schartel, P. Pötschke, U. Knoll, M. Abdel-Goad, Eur. Polym. J. 41 (2005) 1061-1070.

[112] S. Wei, L. Wang, C. Liu, M. Yu, X. Chen, X. Chen, J. Nanosci. Nanotechnol. 16 (2016) 9919-9924.

[113] H. Vahabi, F. Laoutid, E. Movahedifar, R. Khalili, N. Rahmati, C. Vagner, M. Cochez, L. Brison, F. Ducos, M.R. Ganjali, Polym. Adv. Technol. 30 (2019) 2056-2066.

[114] M. Jouyandeh, N. Rahmati, E. Movahedifar, B.S. Hadavand, Z. Karami, M. Ghaffari, P. Taheri, E. Bakhshandeh, H. Vahabi, M.R. Ganjali, K. Formela, M. R. Saeb, Prog. Org. Coat. 133 (2019) 220-228.

[115] A. Gisario, M. Kazarian, F. Martina, M. Mehrpouya, J. Manuf. Syst. 53 (2019) $124-149$.

[116] M. Mehrpouya, A. Dehghanghadikolaei, B. Fotovvati, A. Vosooghnia, S. S. Emamian, A. Gisario, Appl. Sci. 9 (2019) 3865.

[117] L.A. Verhoef, B.W. Budde, C. Chockalingam, B.G. Nodar, A.J. van Wijk, Energy Policy 112 (2018) 349-360.

[118] S.A. Tofail, E.P. Koumoulos, A. Bandyopadhyay, S. Bose, L. O’Donoghue, C. Charitidis, Mater. Today 21 (2018) 22-37.

[119] A.D. Valino, J.R.C. Dizon, A.H. Espera Jr, Q. Chen, J. Messman, R.C. Advincula, Prog. Polym. Sci. (2019) 101162.

[120] H. Wu, W. Fahy, S. Kim, H. Kim, N. Zhao, L. Pilato, A. Kafi, S. Bateman, J. Koo, Prog. Mater. Sci. (2020) 100638.

[121] T. van Manen, S. Janbaz, A.A. Zadpoor, Mater. Today 21 (2018) 144-163.

[122] S.C. Ligon, R. Liska, J. Stampfl, M. Gurr Jr, R. Mülhaupt, Chem. Rev. 117 (2017) 10212-10290.

[123] K.S. Kwok, Q. Huang, M. Mastrangeli, D.H. Gracias, Adv. Mater. Interfaces 7 (2020) 1901677.

[124] C.M. González-Henríquez, M.A. Sarabia-Vallejos, J. Rodriguez-Hernandez, Prog. Polym. Sci. (2019).

[125] B. Furet, P. Poullain, S. Garnier, Addit. Manuf. (2019).

[126] A. Paolini, S. Kollmannsberger, E. Rank, Addit. Manuf. 30 (2019) 100894.

[127] C. Culmone, G. Smit, P. Breedveld, Addit. Manuf. (2019).

[128] T.D. Ngo, A. Kashani, G. Imbalzano, K.T. Nguyen, D. Hui, Compos. Part B Eng. 143 (2018) 172-196.

[129] J. Herzberger, J.M. Sirrine, C.B. Williams, T.E. Long, Prog. Polym. Sci. (2019) 101144.

[130] H. Wu, W. Fahy, S. Kim, H. Kim, N. Zhao, L. Pilato, A. Kafi, S. Bateman, J. Koo, Prog. Mater. Sci. 111 (2020) 100638.

[131] J.R.C. Dizon, A.H. Espera Jr, Q. Chen, R.C. Advincula, Addit. Manuf. 20 (2018) 44-67.

[132] J.W. Stansbury, M.J. Idacavage, Dent. Mater. 32 (2016) 54-64.

[133] F.P. Melchels, J. Feijen, D.W. Grijpma, Biomaterials 31 (2010) 6121-6130.

[134] C. Yang, M. Boorugu, A. Dopp, J. Ren, R. Martin, D. Han, W. Choi, H. Lee, Mater. Horiz. 6 (2019) 1244-1250.

[135] Y. Cho, I. Lee, D.-W. Cho, Microsyst. Technol. 11 (2005) 158-167.

[136] A. Gisario, M. Mehrpouya, E. Pizzi, J. Laser Appl. 29 (2017) 022418.

[137] C. Heller, M. Schwentenwein, G. Russmueller, F. Varga, J. Stampfl, R. Liska, J. Polym. Sci. Part A: Polym. Chem. 47 (2009) 6941-6954.

[138] Y. Sano, R. Matsuzaki, M. Ueda, A. Todoroki, Y. Hirano, Addit. Manuf. 24 (2018) $521-527$.

[139] P. Tesavibul, R. Felzmann, S. Gruber, R. Liska, I. Thompson, A.R. Boccaccini, J. Stampfl, Mater. Lett. 74 (2012) 81-84. 
[140] C. Sun, N. Fang, D. Wu, X. Zhang, Sens. Actuators A Phys. 121 (2005) 113-120.

[141] M. Laschke, M. Rücker, G. Jensen, C. Carvalho, R. Mülhaupt, N.C. Gellrich, M. Menger, J. Biomed. Mater. Res. Part A 85 (2008) 397-407.

[142] X. Wei, L. Zeng, Z. Pei, Am. Soc. Mech. Eng. (2019) p. V02AT02A062.

[143] K. Shahzad, J. Deckers, Z. Zhang, J.-P. Kruth, J. Vleugels, J. Eur. Ceram. Soc. 34 (2014) 81-89.

[144] F. Sillani, R.G. Kleijnen, M. Vetterli, M. Schmid, K. Wegener, Addit. Manuf. 27 (2019) 32-41.

[145] P. Parandoush, D. Lin, Compos. Struct. 182 (2017) 36-53.

[146] J. Bai, R.D. Goodridge, R.J. Hague, M. Song, Polym. Eng. Sci. 53 (2013) 1937-1946.

[147] K. Tan, C. Chua, K. Leong, C. Cheah, P. Cheang, M.A. Bakar, S. Cha, Biomaterials 24 (2003) 3115-3123.

[148] K. Tan, C. Chua, K. Leong, C. Cheah, W. Gui, W. Tan, F. Wiria, Biomed. Mater. Eng. 15 (2005) 113-124.

[149] J.-P. Kruth, L. Froyen, J. Van Vaerenbergh, P. Mercelis, M. Rombouts, B. Lauwers, J. Mater. Process. Technol. 149 (2004) 616-622.

[150] M. Agarwala, D. Bourell, J. Beaman, H. Marcus, J. Barlow, Rapid Prototyp. J. 1 (1995) 26-36.

[151] I. Shishkovsky, I. Yadroitsev, P. Bertrand, I. Smurov, Appl. Surf. Sci. 254 (2007) 966-970.

[152] B. Caulfield, P. McHugh, S. Lohfeld, J. Mater. Process. Technol. 182 (2007) $477-488$.

[153] U. Ajoku, N. Hopkinson, M. Caine, Mater. Sci. Eng. A 428 (2006) 211-216.

[154] H. Zarringhalam, N. Hopkinson, N. Kamperman, J. De Vlieger, Mater. Sci. Eng. A 435 (2006) 172-180.

[155] J.M. Williams, A. Adewunmi, R.M. Schek, C.L. Flanagan, P.H. Krebsbach, S. E. Feinberg, S.J. Hollister, S. Das, Biomaterials 26 (2005) 4817-4827.

[156] J.T. Rimell, P.M. Marquis, J. Biomed. Mater. Res. 53 (2000) 414-420.

[157] M. Schmidt, D. Pohle, T. Rechtenwald, CIRP Annals 56 (2007) 205-208.

[158] J.-P. Kruth, P. Mercelis, J. Van Vaerenbergh, L. Froyen, M. Rombouts, Rapid Prototyp. J. 11 (2005) 26-36.

[159] R. Narayan, Rapid Prototyping of Biomaterials: Techniques in Additive Manufacturing, Woodhead Publishing, 2019.

[160] J.-P. Kruth, G. Levy, F. Klocke, T. Childs, CIRP Annals 56 (2007) 730-759.

[161] N.A. Meisel, C.B. Williams, A. Druschitz, Lightweight metal cellular structures via indirect 3D printing and casting, Proceedings of the International Solid Freeform Fabrication Symposium (2012) 162-176.

[162] Y. Bai, C.B. Williams, Rapid Prototyp. J. 21 (2015) 177-185.

[163] M. Hofmann, 3D Printing Gets a Boost and Opportunities with Polymer Materials, ACS Publications, 2014.

[164] M. Baumers, C. Tuck, R. Hague, Selective heat sintering versus laser sintering: comparison of deposition rate, process energy consumption and cost performance, Sold Freeform Fabrication Symposium (2015).

[165] A.K. Sood, R.K. Ohdar, S.S. Mahapatra, Mater. Des. 31 (2010) 287-295.

[166] S. Janbaz, R. Hedayati, A. Zadpoor, Mater. Horiz. 3 (2016) 536-547.

[167] T. van Manen, S. Janbaz, A.A. Zadpoor, Mater. Horiz. 4 (2017) 1064-1069.

[168] J. Edgar, S. Tint, Johnson Matthey Technol. Rev. 59 (2015) 193-198.

[169] D. Ahn, J.-H. Kweon, J. Choi, S. Lee, J. Mater. Process. Technol. 212 (2012) 339-346.

[170] UL iQ ${ }^{\mathrm{TM}}$ Database, Plastics for Additive Manufacturing, 2020. https://iq.ul. $\mathrm{com} / \mathrm{ul} /$ cert.aspx?ULID $=104113999$.

[171] Clariant, PA666, 2020. https://www.clariant.com/en/Solutions/Products/201 9/03/08/15/39/PA666 GF20 FR LS 3Dprinterfilament.

[172] 3DX Tech Additive Manufacturing, Firewire ${ }^{\circledR}$ Flame Retardant ABS, 2020. htt ps://www.3dxtech.com/firewire-flame-retardant-abs- $1 \mathrm{~kg} /$.

[173] Formfutura, ABSpro Flame Retardant, 2020. https://www.formfutura.com/shop /product/abspro-flame-retardant-black-301.

[174] ECOREPRAP, Flame Retardant PLA Filament, 2020. https://ecoreprap. com/flame-retardant-pla-filament/\#tab-id-1.

[175] Atomic Filament, Flame Retardant Dark Gray ABS FILAMENT, 2020. https://at omicfilament.com/products/flame-retardant-dark-gray-abs-filament?_pos=1\&_s $\mathrm{id}=\mathrm{e} 81317 \mathrm{~b} 63 \& \_\mathrm{ss}=\mathrm{r}$.

[176] Cubicure, Cubicure Evolution FR (flame-retardant), 2020. https://cubicure.com /en/portfolio/materials/cubicure evolutionFR.

[177] Materialise, Datasheets for PA-AF, 2020. https://www.materialise.com/system /files/resources/materialise_datasheets_def_file_PA-AF.PDF.

[178] EOS Company, Polyamide 12., 2020. https://www.eos.info/en/additive-man ufacturing/3d-printing-plastic/sls-polymer-materials/polyamide-pa-12-alumide.

[179] WIND FORM, Flame Retardant Polyamide Based Material Glass Fiber Filled, 2020. http://www.windform.com/PDF/SCHEDA_WF_FR2_ENG.pdf.

[180] DSM, Novamid® AM1030 FR (F), 2019. https://plasticsfinder.com/en/datash eet/Novamid\%C2\%AE\%20AM1030\%20FR\%20(F)/5Ov0r.

[181] Materialise, PA-AF (Previously Called Alumide), 2020. https://www.materialise. $\mathrm{com} / \mathrm{en} / \mathrm{manufacturing} / \mathrm{materials} / \mathrm{pa}$-af.

[182] Strata SYS Direct Manufacturing, Nylon 12 FR, 2017. https://info.stratasysdirect. com/rs/626-SBR-192/images/LS_Nylon_12_FR_Material_Datasheet_201703.pdf.

[183] SENVOL L.L.C., www.senvol.com, 2019.

[184] Y. Guo, C.-C. Chang, G. Halada, M.A. Cuiffo, Y. Xue, X. Zuo, S. Pack, L. Zhang, S. He, E. Weil, Polym. Degrad. Stab. 137 (2017) 205-215.

[185] L. Geoffroy, F. Samyn, M. Jimenez, S. Bourbigot, Polym. Adv. Technol. 30 (2019) 1878-1890.

[186] T.J. Kolibaba, C.-C. Shih, S. Lazar, B.L. Tai, J.C. Grunlan, ACS Mater. Lett. 2 (2019) 15-19.

[187] J. Koo, L. Pilato, G. Wissler, J. Cheng, D. Ho, K. Nguyen, H. Strez, Z. Luo, Flammability and Mechanical Properties of Nylon 11 Nanocomposites,
International SAMPE Symposium and Exhibition (Proceedings), vol 50, Soc. for the Advancement of Material and Process Engineering, 2005, pp. 2457-2470.

[188] J. Koo, S. Lao, K. Ngyuen, J. Cheng, L. Pilato, G. Wissler, M. Ervin, Polyamide nanocomposites for selective laser sintering, 2006 International Solid Freeform Fabrication Symposium (2006).

[189] H. Wu, A. Kafi, H. Kim, R. Shah, S. Bateman, J. Koo, Additive Manufacturing of Flame-Retardant Polyamide 6 Nanocomposites via Fused Filament Fabrication (FFF), SAMPE, 2019, 2019.

[190] H. Wu, A. Kafi, C. Yee, O. Atak, J.H. Langston, R. Reber, J. Misasi, S. Kim, W. P. Fahy, S. Bateman, Ablation Performances of Additively Manufactured HighTemperature Thermoplastic Polymers. AIAA Scitech 2020 Forum, 2020, p. 1125.

[191] A. Kafi, H. Wu, J. Langston, O. Atak, H. Kim, S. Kim, W.P. Fahy, R. Reber, J. Misasi, S. Bateman, J. Appl. Polym. Sci. (2020) 49117.

[192] H. Wu, M. Sulkis, J. Driver, A. Saade-Castillo, A. Thompson, J.H. Koo, Addit. Manuf. 24 (2018) 298-306.

[193] S. Kim, H. Wu, A. Devega, M. Sico, W. Fahy, J. Misasi, T. Dickens, J.H. Koo, J. Mater. Sci. (2020) 1-18.

[194] A. Regazzi, M.F. Pucci, L. Dumazert, S. Buonomo, B. Gallard, R. Ravel, J.M. Lopez-Cuesta, Development of Flame-retarded PLA Compositions by 3D Printing of Core-skin Structures, 2018.

[195] A. Regazzi, M.F. Pucci, L. Dumazert, B. Gallard, S. Buonomo, R. Ravel, J.M. Lopez-Cuesta, Polym. Degrad. Stab. 163 (2019) 143-150.

[196] S.M. Kraft, B.Y. Lattimer, C.B. Williams, Flammability of 3-D Printed Polymers-Composition and Geometry Factors, Proceedings of the 26th Annual International Solid Freeform Fabrication Symposium-An Additive Manufacturing Conference (2016) 2407-2422.

[197] J.A. Block, A Theoretical and Experimental Study of Nonpropagating FreeBurning Fires, Symposium (International) on Combustion, vol 13, Elsevier, 1971, pp. 971-978.

[198] L. Seigel, Civ. Eng. 37 (1967) 65.

[199] L. Seigel, Fire Technol. 6 (1970) 269-278.

[200] W.R. Illeperuma, P. Rothemund, Z. Suo, J.J. Vlassak, ACS Appl. Mater. Interfaces 8 (2016) 2071-2077.

[201] H. Brooks, C. Wright, S. Harris, A. Fsadni, Addit. Manuf. 22 (2018) 138-145.

[202] L. Geoffroy, F. Samyn, M. Jimenez, S. Bourbigot, Polym. Degrad. Stab. 169 (2019) 108992.

[203] L. Chen, H.-B. Zhao, Y.-P. Ni, T. Fu, W.-S. Wu, X.-L. Wang, Y.-Z. Wang, J. Mater. Chem. A 7 (2019) 17037-17045.

[204] S. Hoerold, Flame retardants in 3D printing applications, in: Fire Retardant Plastics Conference, Valencia, Spain, 2019.

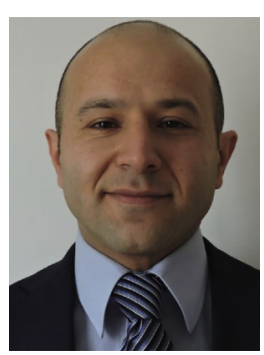

Henri Vahabi received his $\mathrm{PhD}$ in Materials Science from University of Montpellier, France, in 2011. Since then, he jointed to University of Lorraine, France as associate professor. His main research interests include flame retardancy of polymeric materials and nanocomposites. He has authored over 100 peer-reviewed scientific articles/book chapters.

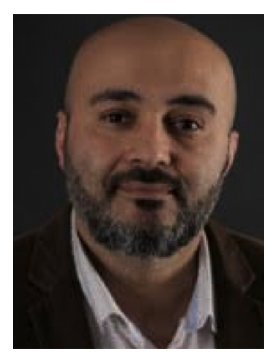

Fouad Laoutid PhD in Polymer Science from University of Montpellier (Ecole des Mines d'Alès), his main research area is the development of new fire safe polymeric materials containing free halogenated flame retardant systems while considering additional functional properties i.e. mechanical and thermal performances. He has in charge of academic and industrial research projects and has more than 60 publications in international journals, 6 chapters of book and is co-inventor of 7 patents. 


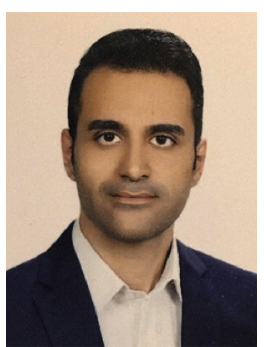

Mehrshad Mehrpouya earned his Ph.D. degree through a fellowship program from Sapienza University of Rome, Italy, in 2017. He is currently an Assistant Professor in the Department of Design, Production, and Management (DPM) at the University of Twente (UT). His research interests are directed toward Advanced Manufacturing, 3D/4D Printing, Functional Materials, and modeling.

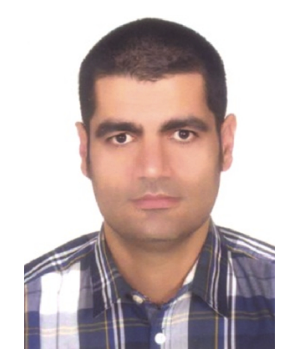

Dr. Mohammad Reza Saeb was born in 1976 in Behshahr, a small yet beautiful city in the north of Iran. He has been invited several times as guest lecturer to do research or teach advanced courses on the analysis of polymer blends and (nano)composites acknowledged by well-known universities in Germany, Poland and France. Structure-property relationship in polymer systems is his particular interest. He defined two universal indices, Cure Index (with Dr. Maryam Jouyandeh) and Flame Retardancy Index (with Dr. Henri Vahabi), which enabled semiqualitative analysis and classification of polymer composites in terms of performance.

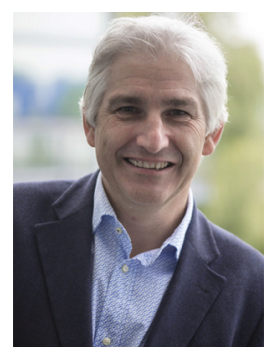

Philippe Dubois, Ph.D. in sciences, is rector-president of University of Mons (Mons, Belgium). He is full professor at Faculty of Sciences where he leads the Laboratory of Polymeric and Composite Materials, Center of Innovation and Research in Materials \& Polymers CIRMAP. His expertise covers organic chemistry; macromolecular chemistry; catalysis in polymer materials; and (reactive) processing of (nano)composites and nanohybrid materials, including biosourced polymers. He has published more than 770 peer-reviewed scientific articles/ book chapters, 11 books and scientific special journal issues $(\mathrm{H}$ index: 102; overall citations: 51,540 ) and is the inventor of 72 patents. 